\title{
Influence of Natural Climate Variability on Extreme Wave Power over Indo-Pacific Ocean Assessed using ERA5
}

Prashant Kumar ( $\sim$ prashantkumar@nitdelhi.ac.in )

National Institute of Technology, Delhi https://orcid.org/0000-0001-8480-7490

\section{Sukhwinder Kaur}

National Institute of Technology Delhi

Evan Weller

University of Auckland

lan R. Young

University of Melbourne

\section{Research Article}

Keywords: Wave power energy, Climate Variability, Generalized extreme value(GEV)distribution, IndoPacific Ocean

Posted Date: April 7th, 2021

DOl: https://doi.org/10.21203/rs.3.rs-372607/v1

License: (9) This work is licensed under a Creative Commons Attribution 4.0 International License. Read Full License

Version of Record: A version of this preprint was published at Climate Dynamics on October 4th, 2021. See the published version at https://doi.org/10.1007/s00382-021-05981-9. 
1

2

3

4

5

6

7

8

9

10

11

12

13

14

15

16

17

18

19

20

21

$22 *$ Corresponding Author

23 Email: prashantkumar@ nitdelhi.ac.in

12

3

4

${ }^{1}$ Department of Applied Sciences, National Institute of Technology Delhi, Delhi, India

${ }^{2}$ School of Environment, University of Auckland, Auckland, New Zealand

${ }^{3}$ Department of Infrastructure Engineering, University of Melbourne, Australia.

Version: 09-03-2021

\section{Assessed using ERA5 \\ Influence of Natural Climate Variability on Extreme Wave Power over Indo-Pacific Ocean} Sukhwinder Kaur ${ }^{1}$, Prashant Kumar ${ }^{1}$, Evan Weller ${ }^{2}$, Ian R. Young ${ }^{3}$ 
27 In recent decades, wave power (WP) energy from the ocean is one of the cleanest renewable energy sources associated with oceanic warming. In Indo-Pacific Ocean, the WP is significantly influenced by natural climate variabilities, such as El Niño Southern Oscillation (ENSO), Indian Ocean Dipole (IOD) and Pacific Decadal Oscillation (PDO). In this study, the impact of major climate variability modes on seasonal extreme WP is examined over the period 1979-2019 using ERA5 reanalysis data and the non-stationary generalized extreme value analysis is applied to estimate the climatic extremes. Independent ENSO influence after removing the IOD trends (ENSO|IOD) on WP are evident over the eastern and central Pacific during December-February (DJF) and March-May (MAM), respectively, which subsequently shifts towards the western

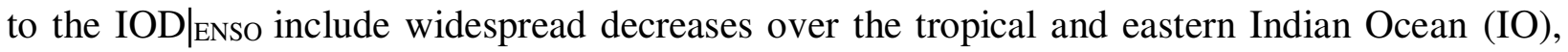
with localized increases only over the South China and Philippine (SCP) seas and Bay of Bengal (BOB) during JJA, and the Arabian Sea during SON. Lastly, for the PDO|ENSo, the significant

41 increases in WP are mostly confined to the Pacific, and most prominent in the North Pacific. 42 Composite analysis of different phase combinations of PDO (IOD) with El Niño (La Niña) reveals stronger (weaker) influences year-round. The response patterns in significant wave height

$44(\mathrm{SWH})$, peak wave period (PWP), sea surface temperatures (SST), and sea level pressure (SLP) helps to explain the seasonal variations in WP.

47 Keywords: Wave power energy, Climate Variability, Generalized extreme value(GEV)distribution, Indo-Pacific Ocean, 


\section{Introduction}

51 The depletion of conventional energy resources and increasing global warming due to the

52 consumption of fossil fuels have prompted interest in renewable energy resources in many

53 countries (Cornett 2008). Among the various renewable energy resources such as wind, solar,

54 hydro-power, etc., wave power is one of the most important and least studied renewable energy

55 resources. Recent studies suggest that the spatial and temporal variations in wave power are

56 induced by natural climate variabilities like El Niño-Southern Oscillation (ENSO), Pacific

57 Decadal Oscillation (PDO), and Atlantic Multidecadal Oscillation (AMO) (Bromirski and Cayan

58 2015; Bromirski et al. 2013; Reguero et al. 2019; Yang and Oh 2020). Therefore, a better

59 comprehension of the wave power and its relation with natural climate variability is essential for

60 social and economic development.

61 WP, which measures the transport of energy that is transmitted by air-to-sea exchanges and used

62 for wave motion (Donelan et al. 1997; Reguero et al. 2019), depends not only on wave height but

63 also on wave period. Moreover, WP represents the accumulated wave energy over periods of

64 time such as months, seasons, and years, unlike other wave climate parameters (e.g., SWH) that

65 must be averaged (Reguero et al. 2019). Therefore, WP can represent the variations in the wave

66 climate better than other wave parameters (e.g., wave height). Yet, to date, continuous efforts

67 have been made to analyze the mean and extreme historical trends in wind and wave climate at

68 the global (Aarnes et al. 2015; Caires et al. 2006; Fan et al. 2012; Gulev and Grigorieva 2004;

69 Meucci et al. 2020; Reguero et al. 2012; Stopa et al. 2013; Young et al. 2011, 2012; Young and

70 Ribal 2019) and regional scale (Allan and Komar 2006; Carter and Draper 1988; Gulev and

71 Grigorieva 2006; Hemer et al. 2008, 2010; Menendez et al. 2008; Wang and Swail 2001, 2006;

72 Wang et al. 2009, 20012; Young 1999; Young and Ribal 2019). In addition, other wave climate 
73 indicators, such as wave period and/or direction, have also been investigated extensively to

74 identify underlying properties in the changes to mean and extreme SWH (Chen et al. 2002;

75 Semedo et al. 2011; Sterl and Caires 2005; Young 1999; Zhang et al. 2011; Zheng et al. 2016).

76 In context of WP, several studies have been carried out previously to analyze the monthly and 77 annual variations in mean wave power at the global scale (Arinaga and Cheung 2012; Barstow et al. 2008; Cornett 2008; Gunn and Stock-Williams 2012; Hulls 1977; Mollison 1986; Mork et al. 79 2010). Further, the seasonal variations in mean wave power were examined by Mackay (2012). However, these analyses were conducted based on either satellite data or wave models such as

81 Wave Watch-III (WW3) and ECMWF WAM for relatively short periods of 6 or 10 or 12 years.

82 Long term seasonal and interannual variations in global mean wave power were investigated by

83 Reguero et al (2015) using WW3 data for a 61-year period (1948-2008). In this regard, 84 numerous regional studies have also been conducted. For example, the North Pacific (NP) 85 (Bromirski et al. 2005, 2013; Yang and Oh 2020), North Atlantic (NA) (Bromirski and Kossin 86 2008; Bromirski and Cayan 2015; Santo et al. 2015), Black Sea (Aydogan et al. 2013), along the 87 Australian coasts (Hemer et al. 2016, 2018), and shelf seas of India (Kumar and Anoop 2015; 88 Sannasiraj and Sundar, 2016; Amrutha et al. 2019; Amrutha and Kumar 2020). However, 89 seasonal/annual variations in extreme WP have not been assessed yet at the global and regional 90 scale.

91 Although many studies have focused on seasonal/annual variations in mean WP as described 92 above, the natural climate variabilities such as the El Niño-Southern Oscillation (ENSO), Indian 93 Ocean Dipole (IOD), and Pacific Decadal Oscillation (PDO), etc. can exert a significant impact 94 on wave climate through large-scale atmospheric circulation patterns with different seasonal and 95 regional features (Hemer et al. 2010; Izaguirre et al. 2010, 2011; Kumar et al 2016, 2019; 
Marshall et al. 2018; Menéndez et al. 2008; Patra et al. 2020; Wandres et al. 2018; Yang and Oh

97 2018). However, influences due to such large-scale natural climate variability modes on WP remains unclear, except for limited regional and global scale studies. For example, using the

99 WW3 wave model for the period 1948-2008, the PDO influence on WP across the NP region was investigated by Bromirski et al. (2013) and NAO influence on WP across the NA region by 101 Bromirski and Cayan (2015) during winter (November-March) and summer (May-September). 102 Recently, Yang and Oh (2020) examined the effect of ENSO and PDO on WP during boreal 103 summer (June-August, JJA) in the western NP. At the global scale, Reguero et al. (2015) 104 analyzed the interrelation between the annual mean WP and fifteen climate variability modes which include ENSO, IOD, and PDO. Recently, the ENSO and Atlantic Multidecadal Oscillation

106 (AMO) influence on annual mean WP have been reported by Reguero et al. (2019). Such studies 107 were predominantly concerned with the seasonal/annual impact of natural climate variability on 108 mean WP.

109 "Extreme" events are significant departures from the normal climate state and often have 110 widespread societal and ecological impacts. The changes in extreme and mean wave 111 characteristics have been reported to be of different nature (Feng et al. 2012; Mori et al. 2010), 112 and are observed to be linked with more frequent extreme events. So, it's crucial to analyze the 113 influence of natural climate variability on extreme parameters, which exert stronger impacts than 114 mean. Further, the simple linear regression analysis is used for mean variables and cannot be 115 applied to extreme variables because of their non-normality nature (Coles 2001), and recent 116 studies have widely used the extreme value theory to investigate the impact of climate variability 117 on extreme parameters such as SWH, wind, wave period, etc. (Izaguirre et al. 2010, 2011; 118 Kharin and Zwiers 2005; Kumar et al 2016, 2019; Menéndez et al. 2008; Min et al. 2013; Patra 
119 et al. 2020; Zhang et al. 2010). But still, none of the previous studies assessed the impact of 120 natural climate variability on extreme WP.

121 This study investigates the seasonal influence of dominant modes of natural climate variability, 122 such as ENSO, IOD, and PDO on extreme WP in the Indo-Pacific Ocean using ERA5 reanalysis 123 data for the 41 year period from 1979-2019. For this purpose, firstly, the four boreal seasons 124 (i.e., December-February (DJF, winter), March-May (MAM, spring), June-August (JJA, 125 summer), and September-November (SON, autumn)) are considered to understand the seasonal 126 influence of natural climate variability on extreme WP and a non-stationary generalized extreme 127 value GEV analysis (Kharin and Zwiers 2005; Zhang et al. 2010; Min et al. 2013) is applied to 128 determine/capture the seasonal extremes. Regions with statistically significant responses at the $1295 \%$ level are marked by hatching. In addition, the seasonal influence of natural climate 130 variability on extreme SWH and Peak Wave Period (PWP) is also investigated to explore the 131 associated underlying mechanisms in enhancing or reducing the WP in the Indo-Pacific Ocean as 132 WP comprises information about SWH and PWP. The seasonal teleconnection patterns of WP 133 and SWH are explained through/by SLP and SST.

134 As different modes of natural climate variability tend to interact with each other in specific 135 seasons (Cai et al. 2011; Kumar et al. 2016, 2019). Therefore, independent analysis of seasonal 136 mean and extreme WP, SWH, and PWP is carried out to assess the role of one variability mode 137 in strengthening and weakening the other variability mode influence in different seasons. 138 Additionally, the composite analysis of mean and extreme WP for the different phase 139 combinations of natural climate variabilities (i.e. ENSO, IOD, and PDO) is also conducted to get 140 further insight into the inter-relation between different variability modes. The novelty of the 141 current study in comparison to previous relevant studies is detailed in Table 1. 
142 The remainder of the paper is structured as follows. Data and methodology are detailed in section

1432 and teleconnection patterns in section 3. Section 4 provides the detailed investigation of the

144 influence of natural climate modes (in particular the ENSO, IOD, and PDO) and their impendent

145 impact on seasonal mean and extreme WP, SWH, and PWP. Composite analysis for different

146 phase combinations of ENSO with IOD and ENSO with PDO is presented in section 5. Section 6

147 provides a summary and conclusions.

\section{2. Data and Methodology}

\section{$149 \quad$ 2.1. Data}

150 The latest reanalysis product from the European Centre for Medium-Range Weather Forecasting 151 (ECMWF), referred to as the ERA5 reanalysis (Hersbach and Dee 2016), is used in the present 152 study to analyze the mean and extreme WP for the 41-year period from 1979 to 2019 over the 153 Indo-Pacific region for the four boreal seasons (i.e., December-February (DJF, winter), March154 May (MAM, spring), June-August (JJA, summer), and September-November (SON, autumn). 155 The ERA5 reanalysis data have several advancements compared to its predecessor, ERA-Interim 156 (Dee et al. 2011). In contrast to ERA-Interim, ERA5 has higher spatial and temporal resolution 157 along with an improved representation of the tropospheric processes, including better 158 representation of tropical cyclones, global balance of precipitation and evaporation cycle etc. In 159 order to measure the WP, the seasonal mean and maxima of SWH (of combined wind waves and 160 swell) and PWP are obtained from the six-hourly SWH and PWP data taken from ERA5.

161 Similarly, the seasonal mean SLP and SST were also derived from 6-hourly SLP and SST data of 162 ERA-5, respectively. In this study, the ERA5 reanalysis data for all the variables were 163 downloaded from the ECMWF website (https://www.ecmwf.int/en/forecasts/datasets/reanalysis- 
164 datasets/era5/) at a horizontal resolution of $0.5^{\circ} \times 0.5^{\circ}$ (i.e. $\mathrm{SWH}$ and PWP) or $0.25^{\circ} \times 0.25^{\circ}$ (i.e., 165 SST and SLP).

\subsection{Climate Indices}

167 Indices used to represent climate variability associated with ENSO, IOD, and PDO over 19791682019 were obtained from several online sources. Overall, ENSO is the dominant coupled ocean169 atmosphere interaction occurring over the equatorial Pacific and significantly affects the 170 interannual climate variability globally (Collins et al. 2010; Stevenson 2012). In order to 171 examine the seasonal ENSO influence, the Niño-3.4 index (referred to as N34 herein) which 172 represents the average SST anomalies over the equatorial eastern Pacific $\left(5^{\circ} \mathrm{N}-5^{\circ} \mathrm{S}, 170^{\circ} \mathrm{W}-\right.$ $173120^{\circ} \mathrm{W}$ ) was obtained from the National Oceanic and Atmospheric Administration/Climate 174 Prediction Center http://www.cpc.ncep.noaa.gov/data/indices/). To quantify the IOD impact, the 175 dipole mode index (DMI) was used (Saji et al., 1999; Webster et al., 1999), which is a measure 176 of the difference between the area-averaged SST anomalies in the western tropical Indian Ocean

177 (TIO) $\left(50^{\circ}-70^{\circ} \mathrm{E}, 10^{\circ} \mathrm{S}-10^{\circ} \mathrm{N}\right)$ and southeastern $\mathrm{TIO}\left(90^{\circ}-110^{\circ} \mathrm{E}, 10^{\circ} \mathrm{S}-\mathrm{Equator}\right)$. Monthly SST 178 anomalies acquired from the extended Reconstructed Sea Surface Temperature (ERSST) dataset 179 to calculate the seasonal DMI index. The PDO index, prescribed as the principal mode of NP 180 monthly SST anomalies poleward of $20^{\circ} \mathrm{N}$ (Zhang et al., 1997), was obtained from the Joint 181 Institute for the Study of the Atmosphere and Ocean (JISAO) at the University of Washington 182 (http://research.jisao.washington.edu/pdo/).

183 Natural climate variability modes can interact with each other during different seasons (Cai et al., 184 2011). Consequently, the independent influence of each should be considered when assessing the 185 impact of each mode. The seasonal correlation coefficients between the detrended N34 and DMI, 
and N34 and PDO indices are shown in Table 2 for the period 1979-2019. A significant positive

187

$$
E=\rho g \int_{0}^{\infty} S(f) d f
$$

203 where $g$ is the acceleration due to gravity, $\rho$ is the sea water mass density $\left(\sim 1028 \mathrm{~kg} / \mathrm{m}^{3}\right)$, $204 S(f)$ denotes the spectral density with respect to frequency $f$, and the $n^{\text {th }}$ order moment is 205

\subsection{Methodology}

\subsubsection{Derivation of Wave Power (WP)}

In essence, WP measures the transmission of energy by/through air-sea exchanges and used for wave motion (Donelan et al. 1997). For irregular waves, the total energy per unit area of water surface (in Joules $/ \mathrm{m}^{2}$ ) is given as:

$$
\text { expressed in terms of spectral density as: }
$$




$$
m_{n}=\int_{0}^{\infty} f^{n} S(f) d f
$$

207 The SWH $\left(H_{S}\right)$ and energy period $\left(T_{e}\right)$ are computed from the integral of the spectral density and 208 expressed in term of moment as follows:

$$
H_{s}=4 \sqrt{m_{0}} \text { and } T_{e}=\frac{m_{-1}}{m_{0}}
$$

210 For each harmonic component of the wave spectrum, its energy travels at the group velocity 211 defined by:

$$
c_{g}(f, d)=\frac{1}{2} \sqrt{\frac{g}{k} \tanh (k d)}\left(1+\frac{2 k d}{\sinh (2 k d)}\right),
$$

213 where $d$ is the water depth, and $k$ is the wave number which is related to the frequency $f$ through

214 the dispersion relation $(2 \pi f)^{2}=g k \tanh (k d)$. The total WP (also referred to as "wave energy

215 flux"), in watts per meter (W/m) of wave crest width at any water depth $d$ is given as

$$
W P=\rho g \int_{0}^{\infty} c_{g}(f, d) S(f) d f
$$

217 On substituting equation (4) into equation (5) and using the dispersion relation:

$$
W P=\frac{\rho g^{2}}{4 \pi} \int_{0}^{\infty} \frac{S(f)}{f}\left[\left(1+\frac{2 k_{f} d}{\sinh \left(2 k_{f} d\right)}\right) \tanh \left(k_{f} d\right)\right] d f
$$

219 For large values of $k_{f} d$, the limits of $\sinh$ and tanh approaches to $\infty$ and 1 , respectively. Thus, equation (6) reduces to: 


$$
W P=\frac{\rho g^{2}}{4 \pi} \int_{0}^{\infty} \frac{S(f)}{f} d f
$$

222 Substituting equations (2) and (3) into equation (7), WP is expressed as:

$$
W P=\frac{\rho g^{2}}{4 \pi}\left(\frac{T_{e} H_{s}^{2}}{16}\right)
$$

224 The energy period is estimated from the spectral shape and other parameters. When PWP ( $\left.T_{p}\right)$ is 225 known, the energy period is estimated by using the following relation (Cornett, 2008):

$$
T_{e}=\alpha T_{p},
$$

227 where $\alpha$ depends on the shape of the wave spectrum and $\alpha$ increases towards unity with 228 decreasing spectral width. Hagerman (2001) assumed $\mathrm{T}_{\mathrm{e}}=\mathrm{T}_{\mathrm{p}}$ in the assessment of the wave 229 energy resources over southern New England. In this study, the same assumption is adopted. On 230 substituting $\mathrm{T}_{\mathrm{e}}=\mathrm{T}_{\mathrm{p}}$ into equation (8), WP is expressed as:

$$
W P=\frac{\rho g^{2}}{4 \pi}\left(\frac{T_{p} H_{s}^{2}}{16}\right) .
$$

\subsubsection{Generalized Extreme Value (GEV) Distribution}

234 Climate extremes are significant departures from the normal climate state and often have 235 widespread societal and ecological impacts. Thus, the correct representation of extreme events is 236 essential to understand their impacts. Extreme value theory provides the statistical description of 237 extremes in stationary and non-stationary processes. However, in the context of environmental 
238 variables (e.g., SWH, temperature, precipitation), a non-stationaryvariable is used (Coles and

239 Casson 1999; Gellens 2002; Nogaj et al. 2007; Kharin and Zwiers 2000, 2005), whereby extreme

240 events are defined by three extreme value distributions, i.e., Gumbel distribution, Fréchet

241 distribution, or Weibull distribution, arising from the limiting theorem of Fisher and Tippett

242 (1928). The three distributions can be combined into a single form, the non-stationary GEV

243 distribution, and its cumulative distribution function is given as:

244

$$
F\left(x, \mu_{t}, \sigma_{t}, \xi_{t}\right)=\left\{\begin{array}{l}
\exp \left[-\exp \left(-\frac{x-\mu_{t}}{\sigma_{t}}\right)\right], \xi_{t}=0 \\
\exp \left[-\left(1+\xi_{t} \frac{x-\mu_{t}}{\sigma_{t}}\right)^{-\xi_{t}^{-1}}\right], \xi_{t} \neq 0,1+\xi_{t} \frac{x-\mu_{t}}{\sigma_{t}}>0
\end{array},\right.
$$

245 where $-\infty<\mu_{t}<\infty, \sigma_{t}>0$, and $-\infty<\xi_{t}<\infty$ represent the location, scale, and shape 246 parameters, respectively. For the non-stationary GEV distribution, the climate variability $v_{t}$ 247 (here, IOD, ENSO, and PDO indices, which are detrended and normalized) that varies with time $248(t)$ is used as a covariate of the GEV parameters. The location parameter $\left(\mu_{t}\right)$ as a function of 249 climate variability is written as:

$$
\mu_{t}=\mu_{0}+\mu_{1}\left(v_{t}-v_{0}\right)
$$

251 where $\mu_{0}$ represents the location parameter at time $t_{0}$, and $\mu_{1}$ denotes the regression coefficient 252 representing the relationship between the climate variable and location parameter. Additionally, 253 the scale and shape parameters can also be expressed as a function of climate variability as 254 follows:

$$
\ln \sigma_{t}=\ln \sigma_{0}+\sigma_{1}\left(v_{t}-v_{0}\right) \text { and } \xi_{t}=\xi_{0}+\xi_{1}\left(v_{t}-v_{0}\right)
$$


256 where $\sigma_{0}$ and $\xi_{0}$ are the scale and shape parameter values at time $t_{0}$, respectively, and $\sigma_{1}$ and $\xi_{1}$

257 are the corresponding regression coefficients. In order to examine the statistical significance of

258 climate variability on extremes, the log-likelihood ratio test is used. The log-likelihood test 259 compares the non-stationary GEV model with the stationary GEV model and assesses the GEV 260 parameters (Kharin and Zwiers 2005; Zhang et al. 2010).

\section{SST and SLP mean Teleconnection}

263 The patterns of seasonal mean SST and SLP regressed onto ENSO|IOD, IOD $\left.\right|_{\mathrm{ENSO}},\left.\mathrm{ENSO}\right|_{\mathrm{PDO}}$, and 264 PDO|ENSO over the period 1979-2019 are shown in Fig.1 and regions with statistically significant 265 responses at the 5\% level are indicated by hatching. Significant canonical responses in SST to 266 ENSO|IOD are evident over the eastern PO (warmer conditions during El Niño) and western PO 267 (colder conditions) throughout the year. In the IO, the strongest signals in SST are found over the majority of the NIO and TIO in DJF and MAM, NIO in JJA, and NIO and western TIO in SON

269 (Fig. 1a). Further, the ENSO|IOD influence on SLP shows high and low pressure anomalies in 270 eastern and western regions of the southern Indo-Pacific Ocean, respectively, during DJF. This 271 anomalous pressure pattern generates strong winds over the southern Indo-Pacific Ocean, leading 272 to an enhancement in both SWH and PWP in DJF (Fig. 1b). Similarly, the Southern Oscillation 273 pattern of the coupled high and low pressure anomalies is also seen in DJF over the western and 274 eastern PO, respectively. This too presumably leads to both strong winds and enhances the wave 275 parameters (i.e., SWH and PWP) over the eastern PO (Fig. 1b). With the progression of the 276 seasons from DJF through to SON, the high and low pressure anomalies shift from the western 277 PO and eastern PO to central-western PO and eastern PO, respectively, during JJA and SON. 
278 Additionally, high pressure anomalies are observed over the eastern parts of the SO, NIO, and

279 TIO, with low pressure anomalies over the central parts of the SO during MAM, JJA, and SON.

280 Such strong responses associated with SLP changes will also lead to strong responses in the 281 winds and wave parameters (Fig. 1b).

282 Significant impacts of IOD $\left.\right|_{\text {ENSO }}$ on SST is predominantly confined to the western IO and AS in 283 DJF, which extend into parts of the tropical Pacific in MAM. During JJA and SON, the IOD|ENSO 284 is associated with positive SST anomalies over the western-to-central IO in JJA and SON (Fig. 285 1a). The corresponding responses in SLP during DJF show high pressure anomalies over most of 286 the tropical and mid-latitude region of the Indo-Pacific Ocean, and low pressure anomalies over 287 the AS and high-latitude region of the Indo-Pacific Ocean. In MAM, the IOD $\mid$ ENSo influence is 288 most significant over the mid-to-high latitudes in both hemispheres. In JJA, high SLP anomalies 289 expand over the mid-latitudes of Indo-Pacific Ocean, from the eastern IO to central PO, and low 290 pressure anomalies strengthen and expand over the western IO. In SON, high SLP anomalies are 291 evident over the eastern IO and tropical PO, and develop over the eastern southern PO, whereas 292 the low pressure anomalies over the western IO are similar to JJA. Such high and low SLP 293 anomalies, with progressing seasonal patterns, will consequently produce strong winds and 294 consequently enhance the wave parameters in the respective regions (Fig. 1b).

295 The ENSO|PDO impact closely resembles that of ENSO|IOD whereby warmer SSTs are evident 296 over the eastern PO and colder SST over the western PO year around (c.f. first and third rows in 297 Fig 1a). In the IO, significant positive signals in SST due to ENSO|PDO are again evident over 298 large parts of the NIO and TIO in most seasons, being weakest in JJA (Fig. 1a). Further, the 299 ENSO|PDO influence on SLP is also consistent with that of ENSO|IOD whereby the significant 300 signals being associated with the widespread high and low pressure anomalies over the western 
301 and eastern Indo-Pacific Ocean, respectively (c.f. first and third rows in Fig. 1b). However, high 302 pressure anomalies are subdued in the western IO during SON for ENSO|PDo compared to that 303 associated with ENSO|IOD. Thus, the above changes of both ENSO|IOD and ENSO|PDO are likely 304 to generate the similar variations in the generated winds and wave fields in the respective 305 regions, except for the western IO.

306 The independent PDO influence (i.e., PDO|ENSO) on SST is observed to induce consistent year307 round pattern with long-term SST increases (warm SST) over the eastern PO (extending towards 308 the west along the equator) and decreases (cold SST) over the western NP and southwest tropical 309 PO (Fig. 1a). This represents the typical pattern associated with a positive PDO. In the IO, the 310 strong PDO|ENSo influences on SST occur over the AS in MAM, NIO and SCP seas in JJA, and 311 BOB and SCP seas in SON (Fig. 1a). The corresponding responses in SLP exhibit an anomalous 312 low pressure over the north and tropical Pacific and an anomalous high pressure over the eastern 313 TIO in DJF (Fig. 1b). In addition, anomalous high and low pressure centers are evident over the 314 south Pacific in DJF. In MAM, positive responses in SLP to the PDO|ENSO are observed over the 315 large section of the tropical and mid-latitude region of the Indo-Pacific Ocean, with counter 316 responses (low-pressure anomalies) over high latitudes of the Indo-Pacific Ocean. In JJA, the 317 PDO|ENso influence on SLP is most significant over the western Pacific Ocean (PO) 318 (high-pressure anomalies) and eastern NP and Southern Ocean (SO) (low-pressure anomalies). 319 These anomalies propagate into the western NP (high-pressure anomalies) and central NP 320 (low-pressure anomalies) in SON. In SON, high and low pressure anomalies are evident over the 321 SO. 


\section{Influence of Indo-Pacific Climate Variability}

325

326

327

328

329

330

331

332

333

334

335

\subsection{ENSO Influence}

Spatial patterns of the seasonal mean and extreme WP (WPavg and WPmax), SWH (Havg and Hmax), and PWP (Pavg and Pmax) responses to independent ENSO|IOD influence (i.e. the independent ENSO influence obtained after the removal of IOD signals) over the period 19792019 in the Indo-Pacific Ocean are shown in Fig. 2. In addition, the original seasonal ENSO influence (i.e., no removal of covarying IOD signals) on the mean and extreme WP, SWH, and PWP is also provided in Supplementary Fig. 1 to assess the role of IOD in strengthening and weakening the ENSO impact. Overall, mean responses in WPavg, Havg, and Pavg were acquired by using linear regression whereas extreme responses in WPmax, Hmax, and Pmax were based on the non-stationary GEV analysis. Regions with statistically significant responses at the 5\% level are indicated by hatching.

Widespread positive responses in WPmax to ENSO|IOD are evident over the eastern Pacific and southern part of the IO (an extension from south of Australia) in DJF (Fig. 2a). As the seasons progress from DJF through to SON, large seasonal variations in WP are observed in both the IO and PO. In the PO, positive amplitudes of the WPmax occur more over the central Pacific in MAM, which shift further towards the western Pacific in JJA and SON (Fig. 2a). The strong increases in extreme WP in the western NP and BOB during JJA, and in the western NP during SON, presumably arises from the enhanced tropical cyclone activities during that time of year (Shanas and Kumar 2014; Yang and Oh 2020, 2018; Zhan et al. 2011). However, WPmax exhibit larger seasonality in the IO compared to the PO. For example, the WP increases over the western TIO in MAM, over the western TIO, BOB, SCP seas in JJA, and over the eastern TIO 
346 during $\mathrm{SON}$ in response to $\left.\mathrm{ENSO}\right|_{\mathrm{IOD}}$ (Fig. 2a). The regression patterns of ENSO|IOD on mean 347 WP are similar to the extreme. Consistently, the ENSO|IOD influence on Havg and Hmax over the 348 Indo-Pacific Ocean (Fig. 2b) shows similar seasonal and regional variations as WPavg and 349 WPmax, due to SWH being a dominating factor in determining the WP (Bromirski et al. 2005, 350 2013; Reguero et al. 2019; Yang and Oh 2020). Lastly, the impact of ENSO|IOD on Pavg and 351 Pmax is found to be largest over the eastern PO in DJF and over the western PO in JJA and SON 352 (Fig 2c). Such regions exhibit a significant relationship, whereby changes to tropical SST 353 anomalies due to the warm ENSO phase resulted in variations in anomalous long PWP. In the IO 354 however, significant increases in Pavg and Pmax are observed over large parts of the IO year355 round due to ENSO|IOD, but more so in DJF and MAM (Fig. 2c).

356 Comparing independent ENSO influences (ENSO|IOD) to the original ENSO signals (c.f. Fig. 2 357 and Supplementary Fig. 1), it is found that WPavg is enhanced more over the eastern TIO in JJA 358 and SON, and over the central NP in SON for the independent ENSO influence. This indicates 359 that the IOD acts to reduce the ENSO impact in these regions during JJA and SON. In addition, 360 enhancement in the independent ENSO influence is also exhibited in the mean and extreme 361 SWH responses when the covarying IOD signal is removed during JJA and SON (c.f. Fig. 2b and 362 Supplementary Fig. 1b). However, positive responses in mean and extreme PWP associated with 363 ENSO in the IO are significantly reduced during SON when the covarying IOD signal is 364 removed (c.f. Fig 2c and Supplementary Fig. 1c). In DJF and MAM, the ENSO|IOD impact on 365 mean and extreme WP, SWH, and PWP exhibits similar regional variations as observed for the 366 complete ENSO signals as the IOD is not active during these seasons.

367 4.2. IOD Influence 
368 Seasonal spatial regression patterns of mean and extreme WP, SWH, and PWP against the 369 independent IOD influence (denoted as IOD|ENSO) after removing the ENSO signal over 1979-

3702019 in the Indo-Pacific Ocean are presented in Fig. 3. Further, the original seasonal IOD 371 influence (here using the DMI) on the mean and extreme WP, SWH, and PWP that include 372 variability due to ENSO is also provided in Supplementary Fig. 2.

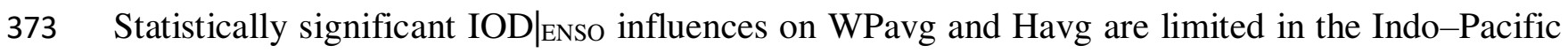
374 Ocean and are generally less intense than ENSO influences (c.f. Fig. 2 and Fig.3). During DJF 375 and MAM, the positive responses of extreme WP and SWH to IOD|ENSo are evident over the SO, 376 and the responses extend into the IO for PWP (Fig 3). Significantly decreased signals are also 377 found over the AS and central-to-western IO during MAM. However, the IOD is not active 378 during this half of the year; therefore, such signals may be related to other variability intrinsic to 379 the IO, such as the Indian Ocean Basin Mode (IOBM), which are shown to prolong ENSO 380 effects (Yuan et al. 2008). During JJA and SON, decreases in WP and SWH are evident over the 381 majority of the eastern IO, with increases only in extremes in the BOB in JJA (related to 382 increased cyclonic activity), and over the AS and southwestern IO in SON (Fig. 3a-b). The 383 opposite occurs for mean and extreme PWP, where weak decreases are found over the entire IO 384 in JJA, but large increases are found over the eastern IO alongside decreases over the western IO 385 in SON. The IOD|ENso influence on extreme WP and SWH is evident over the eastern PO in DJF, 386 over the central north Pacific in MAM, over the western PO in JJA and SON (Fig. 3a,-b). The 387 mean responses to IOD $\left.\right|_{\text {ENSO }}$ are also observed to follow similar patterns as the extreme, except 388 for the western $\mathrm{PO}$ and $\mathrm{BOB}$ in JJA. The western PO and BOB are subject to high WP due to 389 intensified tropical cyclone activity during JJA (Shanas and Kumar 2014; Yang and Oh 2020, 

2018); however, negative amplitudes in these regions suggest that El Niño hampers such activity and resulting in smaller WP.

Overall, an increase in SWH and decrease in PWP over regions such as the BOB and the northwestern Australian coast in DJF are associated with the seasonal increase in small fetch winds (Remya et al. 2020). In addition, significant impact of the IOD|ENSO on SWH is constrained to the eastern IO and BOB in JJA, with decreases in mean PWP. This indicates that whilst swells dominate the IO, wind seas (directly generated and strongly coupled to local winds) are also of 397 importance in JJA during positive IOD events (Remya et al., 2020). In SON, the strongest 398 IOD|ENSO responses in PWP are evident over the entire IO, except the far western IO. However, 399 in the PO, positive responses of PWP to IOD|ENSO occur over the eastern PO except in SON, 400 where decreases in PWP occur over the majority of the PO (Fig.3c).

401 Lastly, comparing independent IOD influences (IOD|ENSo) to the original IOD signals (c.f. Fig. 3 402 and Supplementary Fig. 2), the independent IOD impacts on WP, SWH, and PWP are similar to 403 the complete IOD signal, yet slightly reduced over the entire Indo-Pacific Ocean in DJF and 404 MAM, and over the IO during SON. This emphasizes the significant influence of the IO climate 405 variability over the Indo-Pacific Ocean in DJF and MAM, and over the IO in SON even in the 406 absence of ENSO. In the PO, decreases in WPavg and Havg over the western NP in JJA and 407 SON occur, indicating that ENSO plays a vital role in enhancing the IOD influences in this 408 region (c.f. Fig. 3a-b and Supplementary Fig. 2a-b). Similarly, the negative responses of Pavg to $\left.409 \mathrm{IOD}\right|_{\text {ENSO }}$ are evident over the western NP in JJA and SON, yet they are positive when the 410 covarying ENSO influence is included. This suggests that the PWP signals in the western NP are 411 significantly subdued when the IOD and ENSO are in phase (c.f. Fig. 3c and Supplementary Fig. $4122 \mathrm{c})$. 
414 Seasonal regression patterns of WPavg and WPmax, Havg and Hmax, and Pavg and Pmax 415 against the ENSO|PDO (i.e., ENSO independent of the PDO variability) and PDO|ENSo (i.e., PDO 416 independent of the covarying ENSO signals) over 1979-2019 in the Indo-Pacific Ocean are 417 displayed in Figs. 4 and 5, respectively. In addition, the original ENSO and PDO influence on 418 the mean and extreme WP, SWH, and PWP are also provided in supplementary Fig. 1 and Fig. 3, 419 respectively.

420 Overall, the ENSO|PDO influence on mean WP exhibits similar regional and seasonal variations 421 as in the original ENSO but with a slight reduction in the amplitude throughout the year, apart 422 from the PO in MAM, indicating the dominant impact of ENSO even in the absence of PDO (c.f. 423 Fig. 4a and Supplementary Fig. 1a). In MAM, a decrease in WPavg is evident over the central 424 Pacific. This reveals that PDO enhances the WP over the central Pacific in MAM (c.f. Fig. 4a 425 and Supplementary Fig. 1a). The impact of the ENSO|PDO on WPmax is similar to WPavg yet 426 with stronger amplitudes. The regression patterns of mean and extreme SWH associated with the 427 ENSO|PDO are also consistent with the regression patterns of mean and extreme WP throughout 428 the year (Fig. 4b). Further, the Pavg and Pmax response patterns to ENSO|PDO are similar to 429 those of the original ENSO year-round except in MAM. In MAM, a reduction in response 430 patterns of Pavg and Pmax to ENSO|PDO over the central NP (Fig. 4c) is associated with the SST 431 changes driven by the PDO (Fig. 1a).

432 For the independent PDO influence (i.e. PDO|ENSO), significant increases in mean and extreme 433 WP and SWH are mostly confined to the PO and most prominent in the NP (Fig. 5a-b). Over the $434 \mathrm{IO}$, positive PDO|ENSo responses in WP and SWH are most prevalent during JJA. However, 
strong counter responses (i.e. significant decreases in WPavg and Havg) are evident over the same regions during SON (Fig. 5a-b). Overall, the extreme responses to PDO|ENSo for WP and SWH are consistent with those of the mean responses. The strongest impact of independent PDO (i.e. PDO|ENSO) on Pavg and Pmax is observed over the central NP in DJF and SON, and over the eastern and southern PO in MAM and JJA (Fig. 5c).This suggests that enhanced PWP in these regions are related to the SST changes associated with positive PDO phase (Fig. 1a). In DJF and MAM, PWP decreases and SWH increases in the western NP are related to the seasonal increase in wind seas. In the IO, positive responses to PDO|ENSO in Pavg and Pmax are evident over the mid-latitudes of the SIO in DJF, and over the western IO in MAM. In JJA, an increase in Pavg and Pmax values occurs over the entire IO apart from a small part of the western SIO. Conversely, counter responses in Pavg and Pmax (i.e. decreases over the IO) are found in SON.

Lastly, comparing the seasonal PDO influence independent of ENSO (i.e., PDO|ENSo) to the original PDO signals (c.f. Fig. 5 and Supplementary Fig. 3), it is evident that excluding the cooccurring ENSO signals from PDO reduces the response amplitudes over the eastern PO and mid-latitudes of the SIO in DJF, western TIO, and SIO in MAM, western PO in JJA, and western $\mathrm{PO}$ and SIO in SON. This reveals that ENSO plays a significant role in enhancing PDO influences in these regions during these seasons. However, enhanced WP also occurs over the western PO in MAM and the eastern Pacific in JJA (c.f. Fig. 5 and Supplementary Fig. 3).

\section{Composite Analysis}

\subsection{Composite Analysis of ENSO and IOD}

As various natural climate variabilities modes interact with one another in a particular season. So, the independent influence of ENSO, IOD, and PDO is analyzed above (in section 4). To get 
457 further insight into the interrelation between the various modes of natural climate variability, the 458 composite analysis of the mean and extreme WP for different ENSO and IOD, and ENSO and 459 PDO phase combinations is conducted for the 41 year period over the Indo - Pacific Ocean. In 460 this section composite analysis is conducted between ENSO and IOD. For this, El Niño 461 (ENSO+), La Niña (ENSO-), and positive and negative IOD (pIOD and nIOD, respectively) 462 years are chosen from the detrended and normalized time series of the original indices for those 463 values where ENSO and IOD indices exceeded a threshold value of \pm 0.5 (list of the years is 464 provided in Table. 3). This gives a total of 9, 3, 5, and 9 sample years in JJA and 11, 3, 4, and 12 465 sample years in SON for the combination of El Niño/pIOD, La Niña/pIOD, El Niño/nIOD, and 466 La Niña/nIOD, respectively. The composite patterns of (left panel) mean and (right panel) 467 extreme WP anomalies in (a) JJA and (b) SON for various ENSO and IOD combinations are 468 shown in Fig. 6.

469 The WPavg and WPmax increases during the El Niño/pIOD years and decreases during La 470 Niña/nIOD years over the western PO, BOB, western TIO, and western SIO in JJA and over the 471 western PO in SON (Fig. 6a and b). The combination of an El Niño event with a pIOD (or nIOD) 472 leads to increase in mean and extreme WP over the western NP and counter response is evident 473 for the combination of La Niña with pIOD (or nIOD) in JJA and SON, reveals the strengthening 474 of ENSO in enhancing/reducing WP in western NP (Fig. 6a and b). During out - phase 475 combinations (i.e. El Niño/nIOD and La Niña/pIOD), an increase in mean and extreme WP is 476 observed over the south-east Indo - Pacific Ocean during La Niña/pIOD and decrease during El 477 Niño/nIOD in JJA and SON.

\section{5.2. Composite Analysis of ENSO and PDO}


479 The composite patterns of (left panel) mean and (right panel) extreme WP anomalies in (a) DJF, (b) MAM, (c) JJA, and (d) SON for various ENSO and PDO combinations are displayed in Fig. 7. For composite analysis, El Niño (ENSO+), La Niña (ENSO-), and positive and negative PDO 482 (pPDO and nPDO, respectively) years are chosen from the detrended and normalized time series 483 of the original indices for those values where ENSO and PDO indices exceeded a threshold value 484 of \pm 0.5 (list of the years is provided in Table. 4). This yields a total of $8,5,2$, and 8 sample years 485 in DJF, 13, 5, 3, and 11 sample years in MAM, 7, 3, 6, and 8 sample years in JJA, and 12, 5, 2, 486 and 12 sample years in SON for the combination of El Niño/pPDO, La Niña/pPDO, El 487 Niño/nPDO, and La Niña/nPDO, respectively.

For El Niño/pPDO events, WPavg increases over the eastern PO in DJF, the central NP in MAM, NPO, SIO, BOB, and western TIO in JJA, and western PO in SON and decreases over 490 the NIO, TIO, SCP seas, and western NP in DJF, western NP and eastern SPO in MAM and JJA, 491 and in the eastern PO, NIO, and $\mathrm{TIO}$ and its counter responses are observed during La 492 Niña/nPOD (Fig. 7, left panel). In SIPO and PO apart from the coastal regions of the western $493 \mathrm{NP}$, an El Niño (La Niña) event with a pPDO leads to a significant increase (decrease) in WPavg 494 in DJF (Fig. 7a, left panel). The increase in WPavg is seen over the larger parts of the NIO and 495 TIO in MAM during in-phase combinations (i.e., El Niño/pPDO or La Niña/nPOD) (Fig. 7b, left 496 panel). In western NP, WPavg increases for the combination of El Niño with a pPDO (or nPDO) 497 and decreases for the combination of La Niña with a pPDO (or nPDO) in JJA and SON. This 498 reveals that ENSO is responsible for enhancing/subsiding the WP over the western NP in JJA 499 and SON. Further, a La Niña event associated with pPDO, enhances the WPavg over the IO 500 while, the counter responses are evident for the combination of a La Niña with nPDO in JJA. 501 The combination of an El Niño (or a La Niña) with pPDO, decreases the mean WP over the 
502 larger parts of the IO, while increases for the combination of an El Niño (or a La Niña) with 503 nPDO in SON. When ENSO and PDO are in out phase combinations (i.e. El Niño/nPOD and La

504 Niña/pPOD), the patterns are noisy and even change the sign in DJF, depicts a decrease in WP 505 over the larger parts of the Indo - Pacific Ocean in MAM, and an increase in WPavg over the 506 BOB and western TIO and decrease in WPavg over the eastern PO in JJA. In SON, an enhance 507 in WPavg is observed over the larger parts of the IO, western PO and mid-latitudes of the SPO 508 during El Niño/nPDO events and decreases during La Niña/pPOD (Fig. 7d). The impact of the 509 ENSO and PDO combinations on extreme WP extreme appears over the same region as in the 510 mean WP year around (Fig. 7, right panel).

\section{Summary and Conclusions}

This study investigates the impact of natural climate variability modes such as ENSO, IOD, and PDO on seasonal extreme WP in the Indo-Pacific Ocean using ERA5 reanalysis data over the

514 period 1979-2019. A non-stationary GEV distribution is applied on the seasonal extremes to 515 determine the regions with significant impact, where the natural climate variability modes are 516 taken as the covariates. In addition, the response patterns of SWH, PWP, SST, and SLP to 517 climate variability modes are also evaluate to understand the underlying physical mechanism 518 involved in increasing (or decreasing) the WP. Overall, the strongest ENSO|IOD influence on 519 extreme WP is evident over the eastern Pacific and southern part of the IO (an extension from 520 south of Australia) in DJF, the central Pacific and western TIO in MAM, the western Pacific, 521 western TIO, BOB, SCP seas in JJA, and the western Pacific and eastern TIO in SON. The 522 positive responses of extreme WP to IOD $\left.\right|_{\text {ENSO }}$ are observed over the eastern PO and SO in DJF, 523 the central north Pacific and SO in MAM, the western PO and BOB in JJA, and the southwestern 524 IO in SON whereas, significantly decreased signals are found over the AS and central-to-western 
525 IO during MAM and the western PO in SON. The ENSO|PDO influence on extreme WP exhibits 526 similar regional and seasonal variations as in the original ENSO but with a slight reduction in the 527 amplitude throughout the year apart from the PO in MAM. For the PDO|ENSO influence, 528 significant increases in extreme WP are mostly confined to the PO and most prominent in the

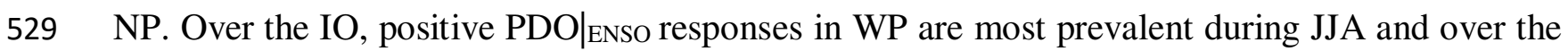
$530 \quad$ SIO and eastern IO.

531 The independent seasonal influence of each climate mode on mean and extreme WP, SWH, and 532 PWP was compared with the original to assess the role of one variability mode in strengthening 533 or weakening the influence of another variability mode. The ENSO influence on extreme WP, 534 independent of IOD, exhibits enhanced WPmax over the eastern TIO in JJA and over the eastern 535 TIO and central NP in SON compared to the original ENSO signals. This implies that the IOD 536 reduces the ENSO signals in these regions during that time of year. The independent IOD impact 537 on WP shows a decrease in WPmax over the western NP in JJA and more so in SON. This 538 suggests that ENSO plays an important role in enhancing the IOD influence in this region during 539 JJA and SON. The independent ENSO influence on WPmax, obtained after the removal of PDO, 540 reveals that the PDO has little to no influence over ENSO signals in the Indo-Pacific Ocean 541 except in MAM. In MAM, the PDO has a strong impact over the influence of ENSO in the PO. 542 Lastly, the independent PDO impact, after removing the ENSO signals, is related to a decrease in 543 WPmax over the eastern PO in DJF, and western NP in JJA and SON. This demonstrates that 544 ENSO is responsible for increasing the WP in these regions during that time of the year. In 545 MAM, ENSO reduces the PDO signals over the PO. In addition, seasonal SLP teleconnection

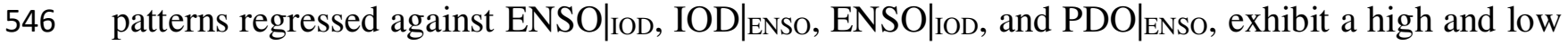
547 pressure anomaly that in turn generates strong winds (Kumar et al 2016, 2019; Patra et al. 2020; 
548 Remya et al., 2020; Yang and Oh 2018) and consequently enhances the wave parameters (i.e. Hs

549 and $\mathrm{Tp}$ ) in the respective localized regions. Overall, the mean WP patterns were highly

550 correlated with the extreme WP patterns year-round. Maximum WP increases were often found

551 during seasons when there are increases in tropical cyclone activity and strong winds, such as

552 NIO during JJA.

553 Composite analysis of mean and extreme WP for the different phase combinations of natural

554 climate variabilities (i.e. ENSO with IOD and ENSO with PDO) strengthen the conclusions

555 drawn from the independent influence patterns (i.e. ENSO, IOD, and PDO separately), which

556 shows that the IOD (or PDO) plays an important role in enhancing or reducing the intensity of

557 ENSO-related responses, or vice versa, depending on the season. During JJA, the IOD enhances

558 (reduces) the ENSO impact on WP when both are in-phase (out-phase) combinations. In SON,

559 (i.e., when ENSOs generally develop and IODs reaches in its mature phase), ENSO is able to

560 enhance the IOD influence on WPavg and WPmax significantly. While, PDO (i.e. pPDO or

561 nPDO events) enhances (reduces) the ENSO influence on WP during El Niño (La Niña) year-

562 round.

563 Acknowledgements

564 All the data (SWH, PWP, SST, and SLP) used in this manuscript is obtained from ERA5

565 reanalysis from the ECMWF website (https://www.ecmwf.int/en/forecasts/datasets/reanalysis-

566 datasets/era5). We would like to acknowledge the working groups for the development of the

567 ERA5 reanalysis datasets. In addition, the current research is supported by Ministry of Earth

568 Sciences (MoES), Government of India and Department of Applied Sciences, National Institute

569 of Technology Delhi. 


\section{References}

573 Aarnes, O. J., Abdalla, S., Bidlot,J.-R.,\&Breivik, Ø. (2015). Marinewind and wave height trends

574 at different ERA-Interim forecastranges. J. $\quad$ Climate, $28 \quad$ (2), 819575 837.https://doi.org/10.1175/JCLI-D-14-00470.1

576 Allan, J.C.,\&Komar, P.D. (2006). Climate controls on US West Coast erosion processes. Journal 577 of coastal research, 22 (3), 511-529.https://doi.org/10.2112/03-0108.1

578 Amrutha, M.M., Kumar, V.S., Bhaskaran, H.,\&Naseef, M. (2019).Consistency of wave power at 579 a location in the coastal waters of central eastern Arabian Sea. Ocean Dynamics, 69(5), 543580 560.https://doi.org/10.1007/s10236-019-01267-1

581 Amrutha, M.M.,\& Kumar, V.S. (2020). Changes in Wave Energy in the Shelf Seas of India 582 during the Last 40 Years Based on ERA5 Reanalysis Data. Energies, 13(1), 583 115.https://doi.org/10.3390/en13010115

584 Arinaga, R.A.,\& Cheung, K.F. (2012). Atlas of global wave energy from 10 years of reanalysis 585 and hindcast data. Renewable Energy, 39(1), 49-64.https://doi.org/10.1016/j.renene.2011.06.039 586 Aydoğan, B., Ayat, B.,\&Yüksel, Y. (2013). Black Sea wave energy atlas from 13 years 587 hindcasted wave data. Renewable energy,57, 436$588 \quad$ 447.https://doi.org/10.1016/j.renene.2013.01.047

589 Barstow, S., Mørk, G., Mollison, D.,\& Cruz, J. (2008).The wave energy resource. In J. Cruz 590 (Eds.), Ocean wave energy (pp. 93-132). Springer. 
591 Bromirski, P.D., Cayan, D.R.,\& Flick, R.E. (2005). Wave spectral energy variability in the 592 northeast of Pacific. Journal Geophysical Research:

593 Oceans, 110(C3).https://doi.org/10.1029/2004JC002398

594 Bromirski, P.D.,\&Kossin, J.P. (2008). Increasing hurricane wave power along the US Atlantic 595 and Gulf coasts. Journal of Geophysical Research:

596 Oceans, 113(C7).https://doi.org/10.1029/2007JC004706

597 Bromirski, P.D., \& Cayan, D.R. (2015). Wave power variability and trends across the 598 NorthAtlantic influenced by decadal climate patterns. Journal of Geophysical Research: 599 Oceans, 120(5), 3419-3443.https://doi.org/10.1002/2014JC010440

600 Bromirski, P.D., Cayan, D.R., Helly, J.,\&Wittmann, P. (2013). Wave power variability and 601 trends across the North Pacific. Journal of Geophysical Research: Oceans, 118(12), 6329602 6348.https://doi.org/10.1002/2013JC009189

603 Caires, S., Swail, V. R.,\& Wang, X. L. (2006). Projection and analysis of extreme wave 604 climate.J. Climate, 19 (21), 5581-5605. https://doi.org/10.1175/JCLI3918.1

605 Cai, W., Sullivan, A.,\& Cowan, T.(2011). Interactions of ENSO, the IOD, and the SAM in 606 CMIP3 models. J. Climate, 24 (6), 1688-1704.https://doi.org/10.1175/2010JCLI3744.1

607 Carter, D.J.T.,\& Draper, L. (1988). Has the north-east Atlantic become 608 rougher? Nature, 332(6164), 494-494.https://doi.org/10.1038/332494a0

609 Chen, G., Chapron, B., Ezraty, R.,\&Vandemark, D. (2002). A global view of swell and wind sea 610 climate in the ocean by satellite altimeter and scatterometer. Journal of Atmospheric and 611 Oceanic Technology, 19(11), 1849-1859.https://doi.org/10.1175/1520-

612 0426(2002)019\%3C1849:AGVOSA\%3E2.0.CO;2 
613 Coles SG (2001) An introduction to statistical modeling of extreme values. Springer, London, $p$ 614 225. https://doi. org/10.1007/978-1-4471-3675-0

615 Coles, S.,\&Casson, E. (1999). Extreme value modelling of hurricane wind speeds. Structural 616 Safety, 20(3), 283-296.https://doi.org/10.1016/S0167-4730(98)00015-0

617 Collins, M., An, S. I., Cai, W., Ganachaud, A., Guilyardi, E., Jin, F. F., et al. (2010). The impact 618 of global warming on the tropical Pacific Ocean and E1 Niño. Nature Geoscience, 3(6), 391-397. 619 https://doi.org/10.1038/ngeo868.

620 Dee, D. P., Uppala, S.M., Simmons, A.J., Berrisford, P., Poli, P., Kobayashi, S., et al.(2011). The 621 ERA-Interim reanalysis: Configuration and performance of the data assimilation system. 622 Quarterly Journal of the royal meteorological society, 137(656), 553-597. doi:10.1002/qj.828 623.

624 Donelan, M.A., Drennan, W.M.,\&Katsaros, K.B. (1997). The air-sea momentum flux in 625 conditions of wind sea and swell. Journal of physical oceanography,27(10), 2087626 2099.https://doi.org/10.1175/1520-0485(1997)027\%3C2087:TASMFI\%3E2.0.CO;2

627 Fan, Y., Lin, S.J., Held, I.M., Yu, Z.,\&Tolman, H.L. (2012).Global ocean surface wave 628 simulation using a coupled atmosphere-wave model. Journal of Climate, 25(18), 6233629 6252.https://doi.org/10.1175/JCLI-D-11-00621.1

630 Feng, X., Tsimplis, M., \& Yelland, M. (2012). Extreme waves at the polar front of North 631 Atlantic from 2000 to 2009 (p. 5719). EGU General Assembly 2012, Vienna, Austria

632 Fisher, R. A., \&Tippett, L. H. C. (1928).Limiting forms of the frequency distributions of the 633 largest or smallest members of a sample. Proceedings of the Cambridge Philosophical Society, $63424,180-190$. 
635 Gellens, D. (2002). Combining regional approach and data extension procedure for assessing 636 GEV distribution of extreme precipitation in Belgium. Journal of Hydrology, 268(1-4), 113-126.

637 Gulev, S. K., \&Grigorieva, V.(2004). Last century changes in ocean wind wave height from 638 global visual wave data.Geophysical Research Letters, 31(24), L24302. 639 https://doi.org/10.1029/2004GL021040

640 Gulev, S.K.,\&Grigorieva, V. (2006). Variability of the winter wind waves and swell in the North 641 Atlantic and North Pacific as revealed by the voluntary observing ship data. Journal of 642 Climate, 19(21), 5667-5685.https://doi.org/10.1175/JCLI3936.1

643 Gunn, K.,\& Stock-Williams, C. (2012).Quantifying the global wave power resource. Renewable 644 Energy, 44, 296-304.https://doi.org/10.1016/j.renene.2012.01.101

645 Hagerman, G.(2001). Southern New England Wave Energy Resource Potential. Proc. Building 646 Energy 2001, Boston, USA.

647 Hersbach, H.,\& Dee, D. (2016). ERA5 reanalysis is in production. ECMWF Newsletter, 147. 648 https://www.ecmwf.int/en/newsletter/147/news/35 era5-reanalysis-production (last access: 14 $649 \quad$ November 2018)

650 Hemer MA, Church JA, Hunter JR (2010) Variability and trends in the directional wave climate 651 of the Southern Hemisphere. Int J Climatol 30:475-491. https://doi.org/10.1002/joc.1900

652

653 Hemer, M.A., Simmonds, I.,\&Keay, K. (2008).A classification of wave generation 654 characteristics during large wave events on the Southern Australian margin. Continental Shelf 655 Research, 28(4-5), 634-652.https://doi.org/10.1016/j.csr.2007.12.004 
656 Hemer, M.A., Manasseh, R., McInnes, K.L., Penesis, I.,\& Pitman, T. (2018). Perspectives on a 657 way forward for ocean renewable energy in Australia. Renewable Energy, 127, 733658 745.https://doi.org/10.1016/j.renene.2018.05.036

659 Hemer, M.A., Zieger, S., Durrant, T., O'Grady, J., Hoeke, R.K., McInnes, K.L.,\&Rosebrock, U. 660 (2016).A revised assessment of Australia's national wave energy resource. Renewable 661 Energy, 114, 85-107.https://doi.org/10.1016/j.renene.2016.08.039

662 Hulls, K. (1977).Wave power.New Zealand Energy Journal,4, 44-48.

663 Izaguirre, C., Méndez, F.J., Menéndez, M.,\&Losada, I.J. (2011). Global extreme wave height 664 variability based satellite data. Geophysical Research

665 Letters, 38(10),L10607.doi:10.1029/2011GL047302

666 Izaguirre, C., Méndez, F. J., Menéndez, M., Luceño, A., \&Losada, I. J. (2010). Extreme wave 667 climate variability in southern Europe using satellite data. Journal of Geophysical 668 Research:Oceans, 115, C04009. https://doi.org/10.1029/2009JC005802.

669 Kharin, V.V.,\&Zwiers, F.W. (2000). Changes in the extremes in an ensemble of transient climate 670 simulations with a coupled atmosphere-ocean GCM. Journal of Climate, 13(21), 3760671 3788.https://doi.org/10.1175/1520-0442(2000)013\%3C3760:CITEIA\%3E2.0.CO;2

672 Kharin, V. V., \&Zwiers, F. W. (2005).Estimating extremes in transient climate change 673 simulations. Journal of Climate, 18(8), 1156-1173. https://doi.org/10.1175/JCLI3320.1

674 Kumar, P., Kaur, S., Weller, E.,\& Min, S.K. (2019). Influence of Natural Climate Variability on 675 the Extreme Ocean Surface Wave Heights Over the Indian Ocean. Journal of Geophysical 676 Research: Oceans, 124(8), 6176-6199.https://doi.org/10.1029/2019JC015391 
677 Kumar, P., Min, S. K., Weller, E., Lee, H., \& Wang, X. L. (2016). Influence of climate 678 variability on extreme ocean surface wave heights assessed from ERA-interim and ERA-20C. 679 Journal of Climate, 29(11), 4031-4046. https://doi.org/10.1175/JCLI-D-15-0580.1

680 Kumar, V.S.,\&Anoop, T.R. (2015). Wave energy resource assessment for the Indian shelf 681 seas. Renewable energy, 76, 212-219.https://doi.org/10.1016/j.renene.2014.11.034

682 Mackay,E. B. L. (2012). Ocean energy:Resource assessment for wave energy. In A. Sayigh 683 (Eds.), Comprehensive Renewable Energy (pp. 11-77).Elsevier.

684 Marshall, A.G., Hemer, M.A., Hendon, H.H.,\&McInnes, K.L. (2018). Southern annular mode 685 impacts on global ocean surface waves. Ocean Modelling, 129, 58686 74.https://doi.org/10.1016/j.ocemod.2018.07.007

687 Menéndez, M., Méndez, F.J., Losada, I.J.,\& Graham, N.E. (2008). Variability of extreme wave 688 heights in the northeast Pacific Ocean based on buoy measurements. Geophysical Research 689 Letters, 35(22), L22607.doi:10.1029/2008GL035394

690 Meucci, A., Young, I.R., Aarnes, O.J.,\&Breivik, O. (2020). Comparison of wind speed and wave 691 height trends from twentieth century models and satellite altimeters.Journal of Climate, 33 (2), 692 611-624.https://doi.org/10.1175/JCLI-D-19-0540.1

693 Min, S.K., Cai, W.,\&Whetton, P. (2013). Influence of climate variability on seasonal extremes 694 over Australia. Journal of Geophysical Research: Atmospheres, 118(2), 643695 654.https://doi.org/10.1002/jgrd.50164

696 Mollison, D.(1986). Wave climate and the wave power resource. In D.V. Evans \& A. F. O. de 697 Falcao (Eds.), Hydrodynamics of ocean wave-energy utilization (pp. 133-156).Springer.

698 Mori N, Yasuda T, Mase H, Tom T, Oku Y (2010) Projection of extreme wave climate change 699 under global warming. Hydrol Res Lett 4:15-19. https://doi.org/10.3178/HRL.4.15 
700 Mork, G., Barstow, S., Kabuth, A.,\& Pontes, M.T. (2010, June). Assessing the global wave

701

702

703

704

705

706

707

708

709

710

711

712

713

714

715

716

717

718

719

720

721

722

energy potential. In ASME 2010 29th International conference on ocean, offshore and arctic engineering (pp. 447-454). American Society of Mechanical Engineers Digital Collection.

Nogaj, M., Parey, S., \&Dacunha-Castelle, D. (2007).Non-stationary extreme models and a climatic application. Nonlinear Processes in Geophysics, 14(3), 305-316. https://doi.org/10.5194/npg-14-305-2007.

Patra, A., Min, S.K. and Seong, M.G., 2020. Climate Variability Impacts on Global Extreme Wave Heights: Seasonal Assessment Using Satellite Data and ERA5 Reanalysis. Journal of Geophysical Research: Oceans, 125(12). https://doi.org/10.1029/2020JC016754.

Reguero, B.G., Losada, I.J.,\& Méndez, F.J. (2015). A global wave power resource and its seasonal, interannual and long-term variability. Applied Energy, 148, 366380.https://doi.org/10.1016/j.apenergy.2015.03.114

Reguero, B.G., Losada, I.J.,\& Méndez, F.J. (2019). A recent increase in global wave power as a consequence of oceanic warming. Nature communications, $10(1), \quad 1$ 14.https://doi.org/10.1038/s41467-018-08066-0

Reguero, B.G., Menéndez, M., Méndez, F.J., Mínguez, R.,\&Losada, I.J. (2012). A Global Ocean Wave (GOW) calibrated reanalysis from 1948 onwards. Coastal Engineering, 65, 3855.https://doi.org/10.1016/j.coastaleng.2012.03.003

Remya, P.G., Kumar, B.P., Srinivas, G.,\& Nair, T.M. (2020). Impact of tropical and extra tropical climate variability on Indian Ocean surface waves. Climate Dynamics, 54(11-12), 49194933.https://doi.org/10.1007/s00382-020-05262-x

Saji,N.H.,Goswami,B.N.,Vinayachandran,P.N.,\&Yamagata,T.(1999).Adipolemodeinthetropicall ndianOcean. Nature,401(6751), 360-363. https://doi.org/10.1038/43854. 
723 Santo, H., Taylor, P.H., Woollings, T.,\& Poulson, S. (2015).Decadal wave power variability in

724 the North-East Atlantic and North Sea. Geophysical Research Letters, 42(12), 4956725 4963.doi:10.1002/2015GL064488.

726 Sannasiraj, S.A.,\&Sundar, V. (2016). Assessment of wave energy potential and its harvesting 727 approach along the Indian coast. Renewable energy, 99,398728 409.https://doi.org/10.1016/j.renene.2016.07.017

729 Semedo, A., Sušelj, K., Rutgersson, A.,\&Sterl, A. (2011). A global view on the wind sea and 730 swell climate and variability from ERA-40. Journal of Climate, 24(5),1461731 1479.https://doi.org/10.1175/2010JCLI3718.1

732 Shanas, P. R., \& Kumar, V. S. (2014). Trends in surface wind speed and significant wave height 733 as revealed by ERA-Interim wind wave hindcast in the Central Bay of Bengal. International 734 Journal of Climatology, 35(9), 2654-2663.doi: 10.1002/joc.4164

735 Sterl, A.,\&Caires, S. (2005). Climatology, variability and extrema of ocean waves: The 736 Web-based KNMI/ERA-40 wave atlas. International Journal of Climatology: A Journal of the 737 Royal Meteorological Society, 25(7),963-977.doi: 10.1002/joc.1175

738 Stevenson, S. L. (2012). Significant changes to ENSO strength and impacts in the twenty-first 739 century: Results from CMIP5. Geophysical Research Letters, 39, L17703. 740 https://doi.org/10.1029/2012GL052759

741 Stopa, J. E., Cheung, K. F.,Tolman, H. L.,\& Chawla, A.(2013) Patterns and cycles in the Climate 742 Forecast System Reanalysis wind and wave data.Ocean Modelling, 70, 207-220. 743 https://doi.org/10.1016/j.ocemod.2012.10.005. 
744 Stuecker, M.F., Timmermann, A., Jin, F.F., Chikamoto, Y., Zhang, W., Wittenberg, A.T., et 745 al.(2017). Revisiting ENSO/Indian Ocean dipole phase relationships. Geophysical Research $746 \quad$ Letters, 44(5), 2481-2492.

747 Wandres, M., Pattiaratchi, C., Hetzel, Y.,\&Wijeratne, E.M.S. (2018). The response of the 748 southwest Western Australian wave climate to Indian Ocean climate variability. Climate 749 dynamics, 50(5-6), 1533-1557.

750 Wang, X. L., \&Swail, V. R.(2001). Changes of extreme wave heights in northern hemisphere 751 oceans and related atmospheric circulation regimes.Journal of climate, 14, 2204-2221.

752 Wang, X. L., \&Swai, V. R.(2006). Historical and possible future changes of wave heights in 753 northern hemisphere ocean InW. Perrie (Eds.),Atmosphere Ocean Interactions(pp. 240) Wessex 754 Institute of Technology Press, Southampton, U.K.

755 Wang, X. L., Feng, Y.,\&Swail, V. R.(2012). North Atlantic wave height trends as reconstructed 756 from the $20^{\text {th }}$ century reanalysis, Geophysical Research Letters, 39, $757 \quad$ L18705.doi:10.1029/2012GL053381.

758 Wang, X. L., Swail, V. R.,Zwiers, F. W., Zhang, X.,\& Feng, Y.(2009). Detection of external 759 influence on trends of atmospheric storminess and ocean wave height.Climate Dynamics,32, 760 189-203.doi:10.1007/s00382-008-0442-2.

761 Webster, P. J., Moore, A. M., Loschnigg, J. P., \&Leben, R. R. (1999).Coupled ocean-atmosphere 762 dynamics in the Indian Ocean during 1997-98. Nature, 401(6751), 356-360. 763 https://doi.org/10.1038/43848.

764 Yang, S.,\& Oh, J. (2020).Effects of modes of climate variability on wave power during boreal 765 summer in the western North Pacific. Scientific reports, 10(1),1-10. 
Yang, S., \& Oh, J. (2018). Long-Term Changes in the Extreme Significant Wave Heights on the

767 Western North Pacific: Impacts of Tropical Cyclone Activity and ENSO. Asia-Pacific Journal of

768 Atmospheric Sciences, 54(1), 103-109.

769 Young, I. R. (1999) Seasonal variability of the global ocean wind and wave climate.

770 International Journal of Climatology, 19(9), 931-950.

771 Young, I. R., Zieger, S., \&Babanin, A. V.(2011): Global trends in wind speed and wave

772 height.Science, 332, 451-455. doi:10.1126/science.1197219.

773 Young, I. R., Vinoth, J., Zieger, S., \&Babanin, A. V.(2012). Investigation of trends in 774 extremevalue wave height and wind speed, Journalof Geophysical Research. 117, 775 C00J06.doi:10.1029/2011JC007753.

776 Young, I.R.,\&Ribal, A. (2019).Multiplatform evaluation of global trends in wind speed and 777 wave height. Science, 364(6440), 548-552.

778 Yuan, Y., Zhou, W., Chan, J. C. L., \& Li, C.(2008). Impacts of the basin-wide Indian Ocean 779 SSTA on the South China Sea summer monsoon onset. International Journal of Climatology: A 780 Journal of the Royal Meteorological Society,28(12), 1579-1587. 781 https://doi.org/10.1002/joc.1671.

782 Zhang, J., Wang, W.,\& Guan, C. (2011).Analysis of the global swell distributions using 783 ECMWF Re-analyses wind wave data. Journal of Ocean University of China, 10(4), 325-330.

784 Zhang,X.B.,Wang,J.F.,Zwiers,F.W.,\&Groisman,P.Y.(2010).Theinfluenceoflarge-scaleclimatevar 785 iabilityonwintermaximumdaily precipitation over North America. Journal of Climate, 23(11), 786 2902-2915. https://doi.org/10.1175/2010JCLI3249.1.

787 Zhang, Y., Wallace, J. M.,\&Battisti, D. S.(1997) ENSO-like interdecadal variability: 1900-93. 788

Journal of Climate, 10, 1004-1020.doi:10.1175/1520-0442(1997)010,1004:ELIV.2.0.CO;2. 
789 Zheng, K., Sun, J., Guan, C.,\& Shao, W. (2016).Analysis of the global swell and wind sea

790 energy distribution using WAVEWATCH $\quad$ III. Advances in

$791 \quad$ Meteorology.https://doi.org/10.1155/2016/8419580

792 
793 Table1. A list of previous studies on natural climate variability influence on WP in comparison 794 with the current study

\begin{tabular}{|c|c|c|c|c|c|}
\hline Reference & $\begin{array}{c}\text { Data } \\
\text { (Period) }\end{array}$ & (Season)Variables & $\begin{array}{c}\text { Climate } \\
\text { Variability }\end{array}$ & $\begin{array}{l}\text { Analysis } \\
\text { Domain }\end{array}$ & Analysis Method \\
\hline $\begin{array}{l}\text { Bromirski } \\
\text { et al. (2013) }\end{array}$ & $\begin{array}{l}\text { WW3 wave } \\
\text { model } \\
\text { (1948-2008) }\end{array}$ & $\begin{array}{c}\text { (winter and } \\
\text { summer) } 90^{\text {th }} \\
\text { percentile } \\
\text { SWH, PWP, WP }\end{array}$ & $\begin{array}{l}\text { PDO, ENSO, } \\
\text { PNA }\end{array}$ & North Pacific & $\begin{array}{l}\text { Linear trend and } \\
\text { EOF }\end{array}$ \\
\hline $\begin{array}{l}\text { Bromirski } \\
\text { and Cayan } \\
(2015)\end{array}$ & $\begin{array}{l}\text { WW3 wave } \\
\text { model } \\
\text { (1948-2008) }\end{array}$ & $\begin{array}{c}\text { (winter and } \\
\text { summer) } 90^{\text {th }} \\
\text { percentile } \\
\text { SWH, PWP, WP }\end{array}$ & $\begin{array}{l}\text { NAO, PNA, } \\
\text { PDO, ENSO }\end{array}$ & North Atlantic & $\begin{array}{l}\text { Linear trend and } \\
\text { EOF }\end{array}$ \\
\hline $\begin{array}{l}\text { Reguero et } \\
\text { al. (2015) }\end{array}$ & $\begin{array}{l}\text { WW3 wave } \\
\text { model } \\
\text { (1948-2008) }\end{array}$ & $\begin{array}{c}\text { (Annual) mean } \\
\text { SWH, MWP, WP }\end{array}$ & $\begin{array}{c}\text { AO, AMO, EA, } \\
\text { NAO, SOI, } \\
\text { TNA, PNA, } \\
\text { WP, EP-NP, } \\
\text { SAM, SCA, } \\
\text { DMI }\end{array}$ & Global & $\begin{array}{l}\text { Correlation } \\
\text { analysis }\end{array}$ \\
\hline $\begin{array}{l}\text { Reguero et } \\
\text { al. (2019). }\end{array}$ & $\begin{array}{l}\text { WW3 wave } \\
\text { model } \\
\text { (1948-2008), } \\
\text { satellite } \\
\text { altimetry } \\
\text { (1992-2008) }\end{array}$ & $\begin{array}{l}\text { (Annual) mean } \\
\text { SWH, MWP, WP }\end{array}$ & $\begin{array}{l}\text { ENSO and } \\
\text { AMO }\end{array}$ & Global & Linear trend \\
\hline $\begin{array}{l}\text { Yang \& Oh } \\
(2020)\end{array}$ & $\begin{array}{l}\text { WW3 wave } \\
\text { model } \\
\text { (1979-2009) }\end{array}$ & $\begin{array}{c}\text { (summer) } 99^{\text {th }} \\
\text { percentile } \\
\text { SWH, PWP, WP }\end{array}$ & ENSO, PDO & western NP & $\begin{array}{l}\text { Regression } \\
\text { analysis, } \\
\text { Composite } \\
\text { analysis (ENSO } \\
\text { and PDO) }\end{array}$ \\
\hline $\begin{array}{l}\text { Recent } \\
\text { study }\end{array}$ & $\begin{array}{l}\text { ERA5 } \\
(1979-2019)\end{array}$ & $\begin{array}{c}\text { (seasonal) mean } \\
\text { and extreme SWH, } \\
\text { PWP, WP }\end{array}$ & $\begin{array}{l}\text { ENSO, IOD, } \\
\text { PDO }\end{array}$ & Indo-Pacific & $\begin{array}{l}\text { Non-stationary } \\
\text { GEV, Composite } \\
\text { analysis (ENSO } \\
\text { with IOD and } \\
\text { PDO) }\end{array}$ \\
\hline
\end{tabular}


Table 2: Correlation coefficients between the seasonal N34 with DMI and PDO indices for the period 1979-2019. All indices are linearly detrended. Statistically significant correlations at the $5 \%$ and $1 \%$ significance levels are marked with $*$ and $* *$, respectively.

\begin{tabular}{|c|c|c|}
\hline & N34- DMI & N34 - PDO \\
\hline DJF & 0.071 & $0.397^{* *}$ \\
\hline MAM & -0.125 & $0.458^{* *}$ \\
\hline JJA & $0.312^{*}$ & $0.437^{* *}$ \\
\hline SOA & $0.620^{* *}$ & $0.545^{* *}$ \\
\hline
\end{tabular}

800

801

Table 3: List of years when a combination of El Niño or La Niña and/or positive or negative 803 IOD events greater than plus or minus one-half standard deviation occurred during the period 804 1979-2019 for (a) JJA, and (b) SON.

\begin{tabular}{|c|c|c|}
\hline (a) JJA & ENSO(+) or El Niño & ENSO(-) or La Niña \\
\hline DMI(+) or pIOD & $\begin{array}{c}1982,1983,1991,1993,1994, \\
1997,2012,2015,2019\end{array}$ & $1999,2007,2008$ \\
\hline DMI(-) or nIOD & $1990,1992,2002,2004,2009$ & $\begin{array}{c}1981,1984,1989,1995, \\
1996,1998,2010,2013,2016\end{array}$ \\
\hline \multicolumn{2}{|c|}{ ENSO(+) or El Niño } & ENSO(-) or La Niña \\
\hline (b) SON & $1982,1986,1987,1991,1994$, & $1983,1985,2011$ \\
\hline DMI(+) or pIOD & $1997,2002,2006,2015,2018,2019$ & $1981,1984,1988,1989$, \\
1 & $1995,1996,1998,1999$, \\
DMI(-) or nIOD & & $2001,2005,2010,2016$ \\
\hline
\end{tabular}

805

806

807

808 


\begin{tabular}{|c|c|c|}
\hline (a) DJF & ENSO(+) or El Niño & ENSO(-) or La Niña \\
\hline PDO $(+)$ or pPDO & $\begin{array}{l}\text { 1986, 1987, 1997, 2002, 2009, } \\
2014,2015,2018\end{array}$ & 1983, 1984, 1985, 2005, 2017 \\
\hline PDO(-) or nPDO & 1990,1994 & $\begin{array}{c}\text { 1988, 1998, 1999, 2007, 2008, } \\
\text { 2010, 2011, } 2012\end{array}$ \\
\hline (b) MAM & ENSO(+) or El Niño & ENSO(-) or La Niña \\
\hline PDO(+) or pPDO & $\begin{array}{l}\text { 1983, 1987, 1992, 1993, 1994, } \\
\text { 1995, 1997, 1998, 2005, 2015, } \\
\text { 2016, 2017, } 2019\end{array}$ & 1981, 1984, 1986, 1988, 1996 \\
\hline PDO(-) or nPDO & $1982,1991,2002$ & $\begin{array}{c}1985,1989,1999,2000,2001, \\
2007,2008,2009,2011,2012,2013\end{array}$ \\
\hline (c) JJA & ENSO(+) or El Niño & ENSO(-) or La Niña \\
\hline PDO(+) or pPDO & $\begin{array}{c}1983,1987,1992,1993,1997, \\
2015,2019\end{array}$ & $1995,2007,2016$ \\
\hline PDO(-) or nPDO & $\begin{array}{c}1982,1991,1994,2002 \\
2009,2012\end{array}$ & $\begin{array}{c}1984,1998,1999,2000,2008, \\
2010,2013 \\
\end{array}$ \\
\hline (d) $\mathrm{SON}$ & ENSO(+) or El Niño & ENSO(-) or La Niña \\
\hline PDO $(+)$ or $\mathbf{p P D O}$ & $\begin{array}{c}1979,1986,1987,1991,1997 \\
2002,2003,2009,2014 \\
2015,2018,2019\end{array}$ & 1983, 1984, 1995, 2016, 2017 \\
\hline PDO(-) or nPDO & 1994, 2006 & $\begin{array}{l}1985,1988,1989,1998,1999, \\
2000,2001,2005,2007,2008, \\
2010,2011\end{array}$ \\
\hline
\end{tabular}

Table 4: List of years when a combination of El Niño or La Niña and/or positive or negative PDO events greater than plus or minus one-half standard deviation occurred during the period 1979-2019 for (a) DJF, (b) MAM, (c) JJA, and (d) SON. 


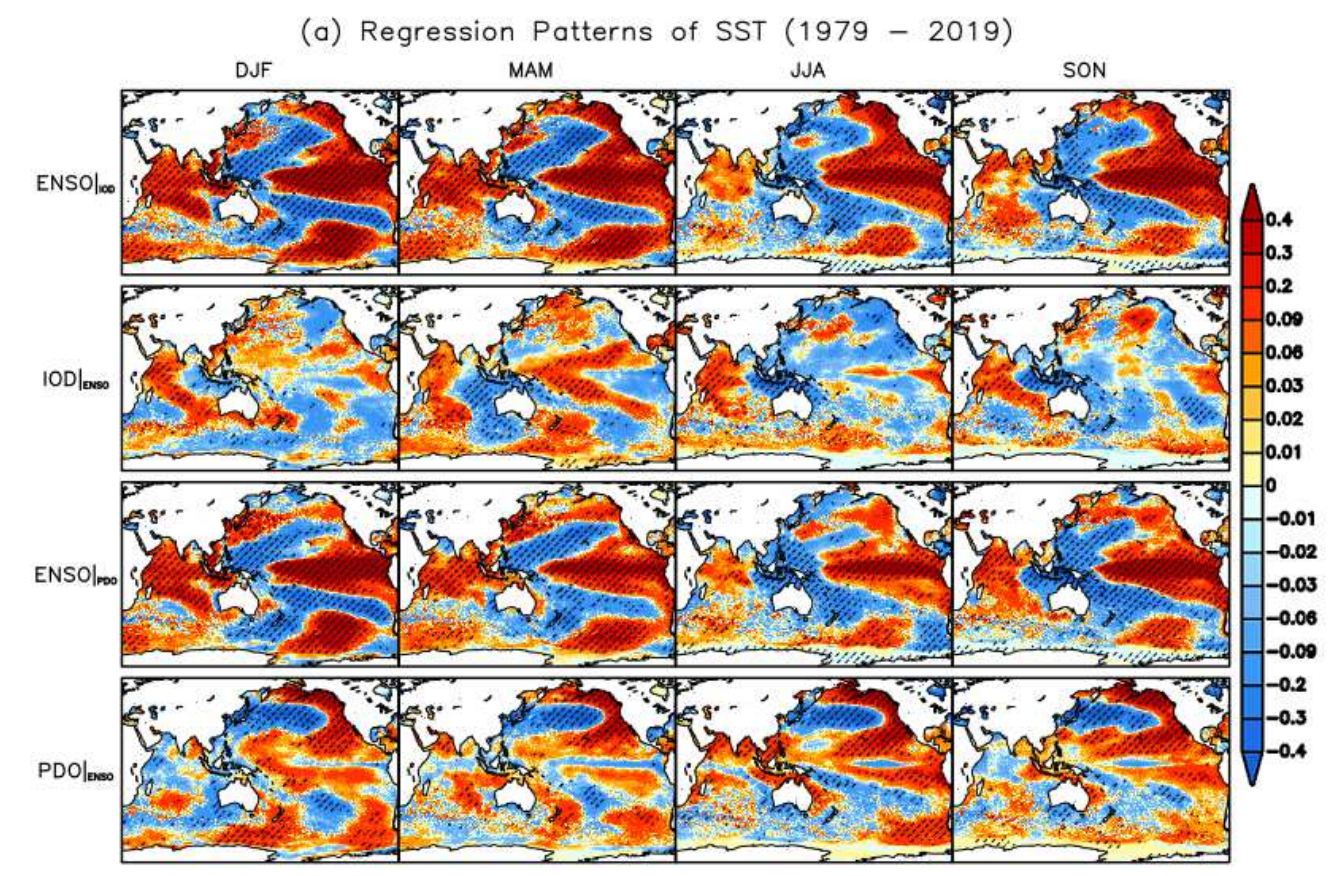

(b) Regression Patterns of SLP (1979 - 2019)

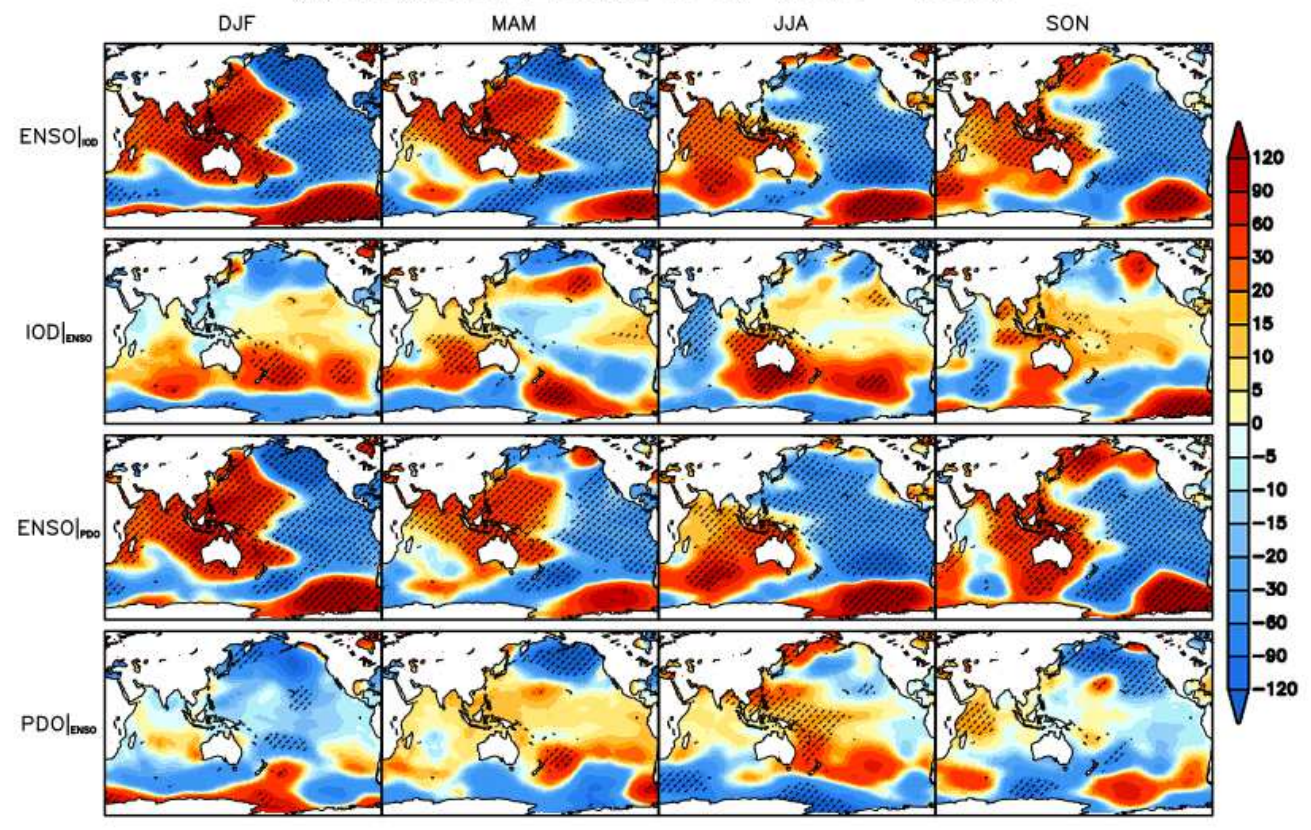

819 Figure 1. Seasonal regression patterns of mean (a) SST (in K) and (b) SLP (in Pa) onto

820 ENSO|IOD, IOD $\left.\right|_{\mathrm{ENSO}},\left.\mathrm{ENSO}\right|_{\mathrm{PDO}}$, and PDO|ENSO in the Indo-Pacific Ocean over the period 1979-

821 2019. Hatching represents the statistically significant regions at the 5\% level. 


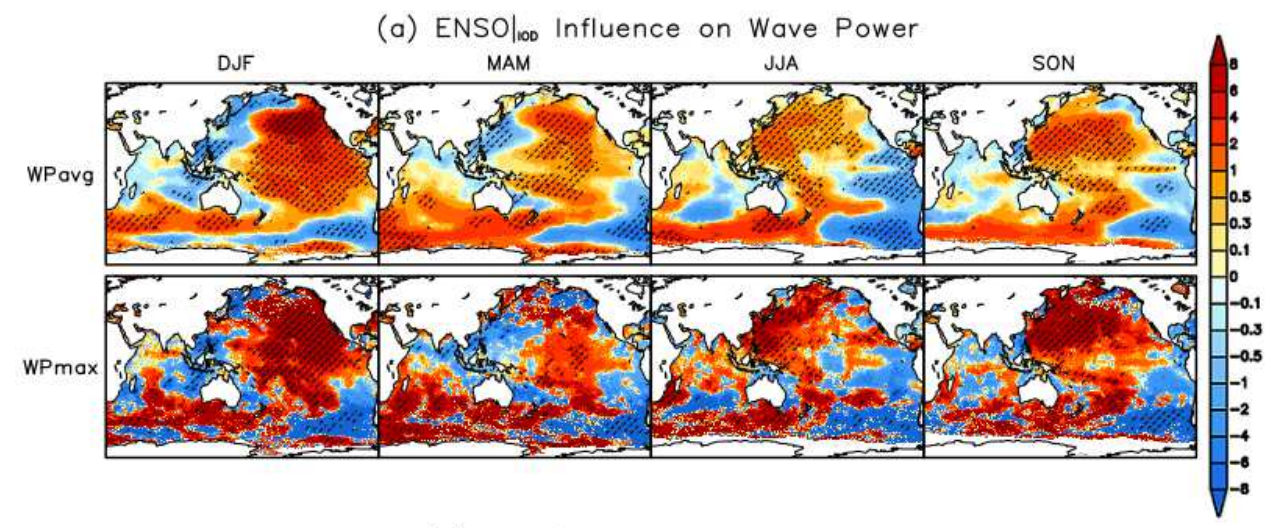

(b) ENSO| 100 Influence on SWH

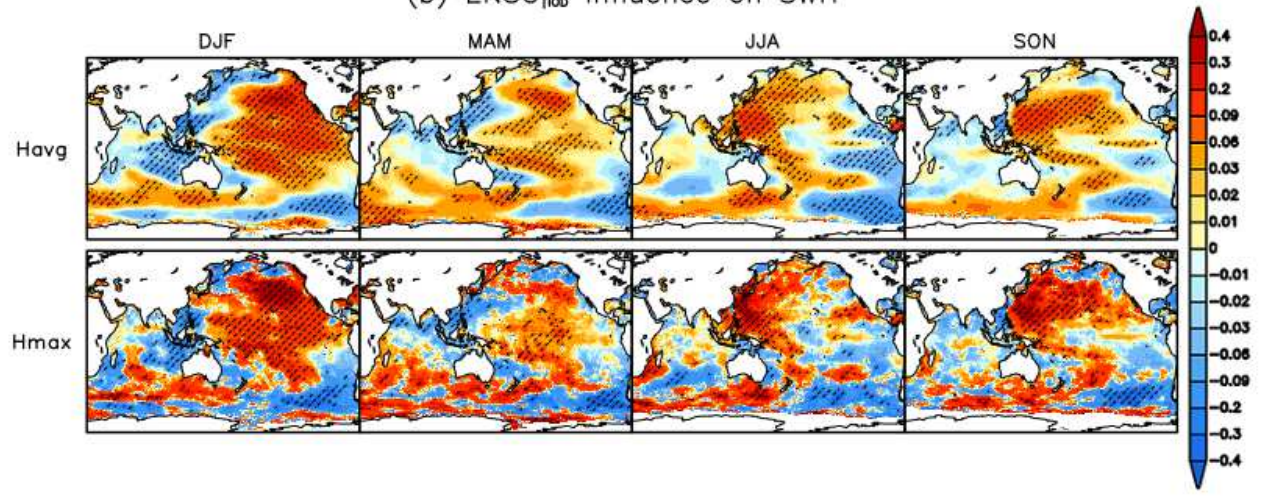

(c) ENSO| 100 Influence on Peak Wave Period

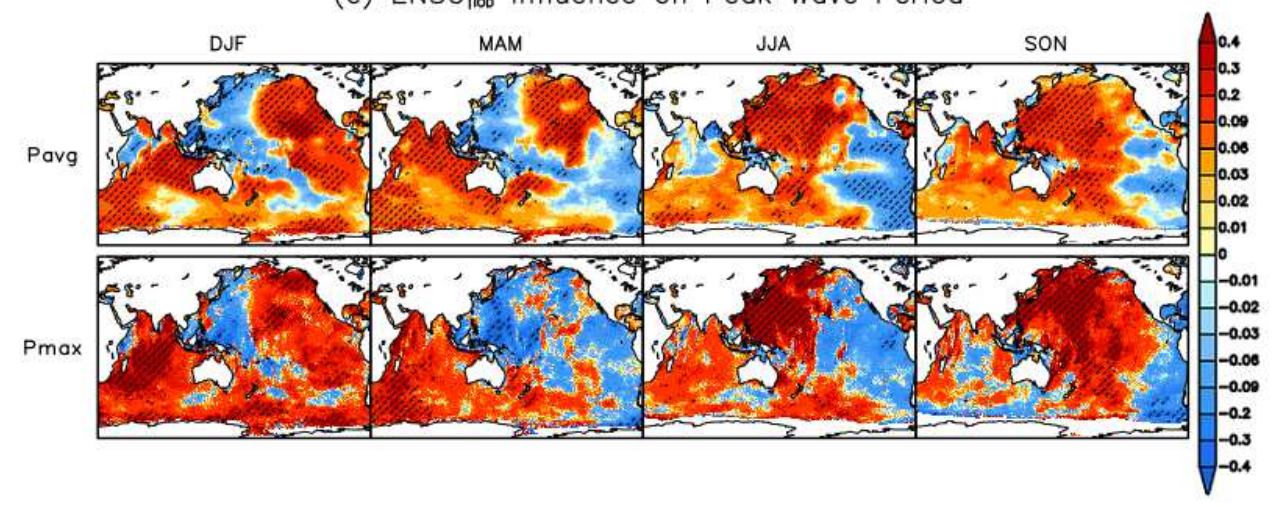

823 Figure 2. The seasonal ENSO influence independent of IOD (denoted as ENSO|IOD), obtained

824 after the removal of IOD signals, on the mean and extreme WP (i.e., WPavg and WPmax), SWH

825 (Havg and Hmax) and PWP (Pavg and Pmax) in the Indo-Pacific Ocean over the period 1979-

826 2019. Hatching represents statistically significant regions at the 5\% level. The unit of WP, SWH

827 and PWP are given as kilowatts per meter $(\mathrm{kW} / \mathrm{m})$, meter $(\mathrm{m})$ and seconds $(\mathrm{s})$. 
(a) $\left.I O D\right|_{\text {Enso }}$ Influence on Wave Power

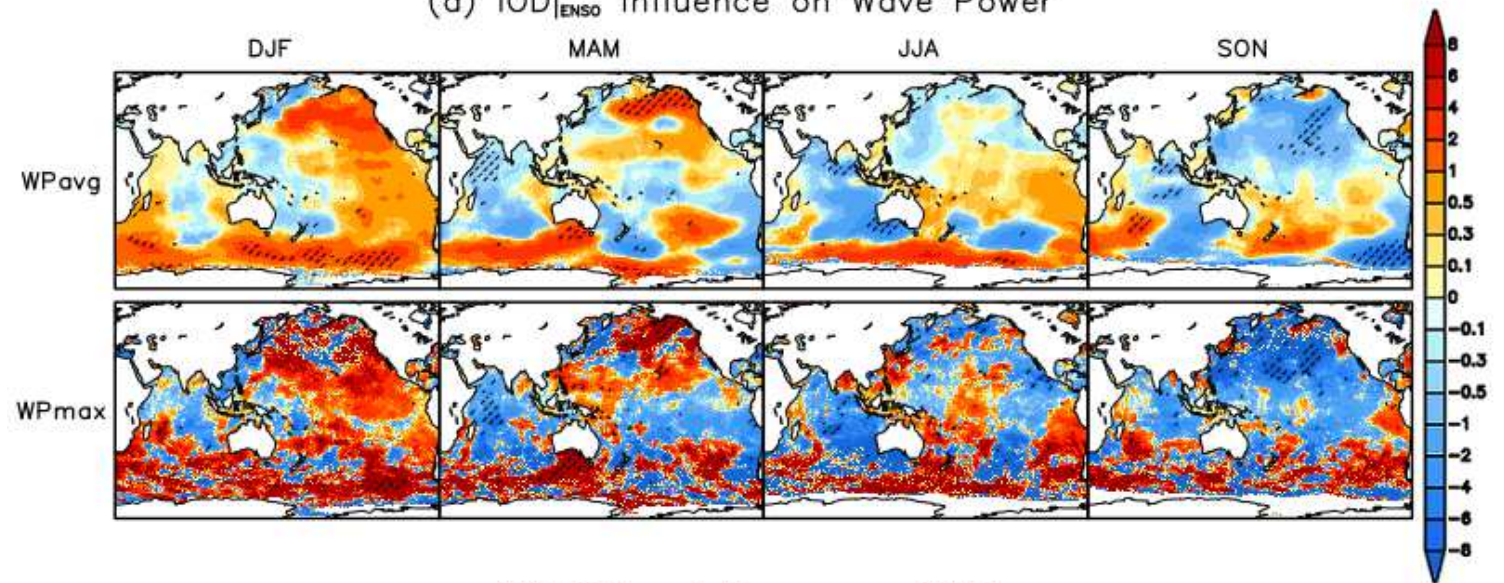

(b) $\left.I O D\right|_{\text {ENso }}$ Influence on SWH

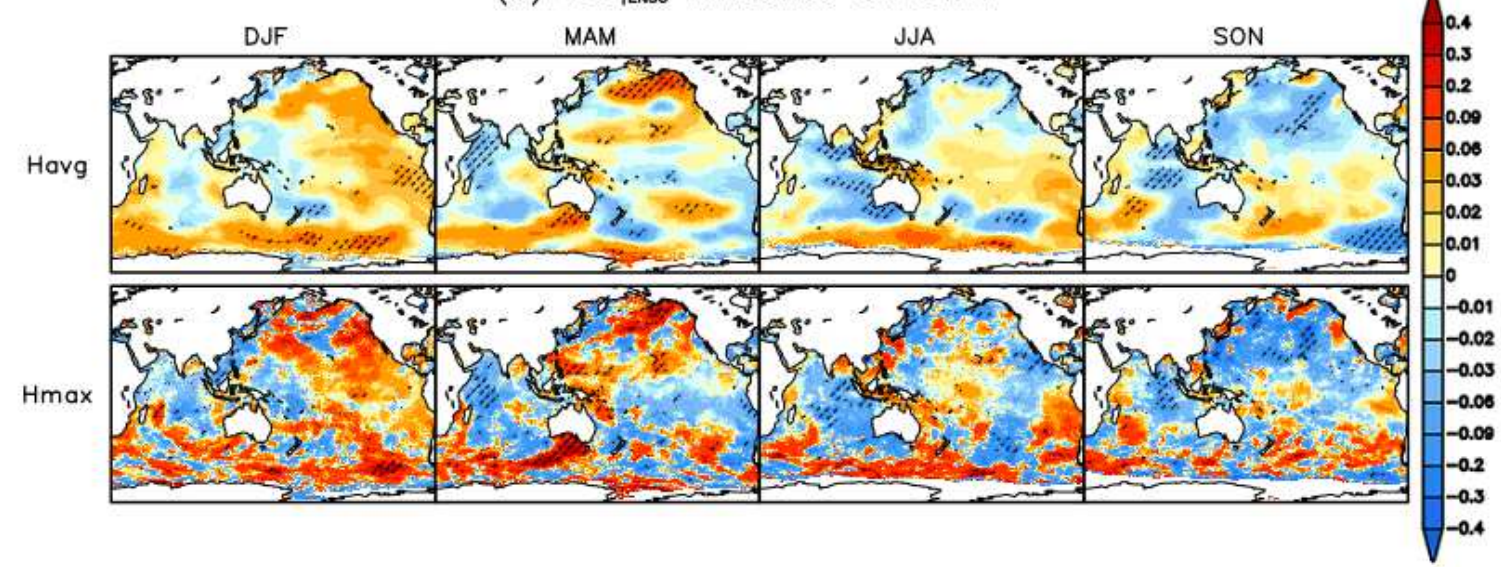

(c) $\left.I O D\right|_{\text {Enso }}$ Influence on Peak Wave Period

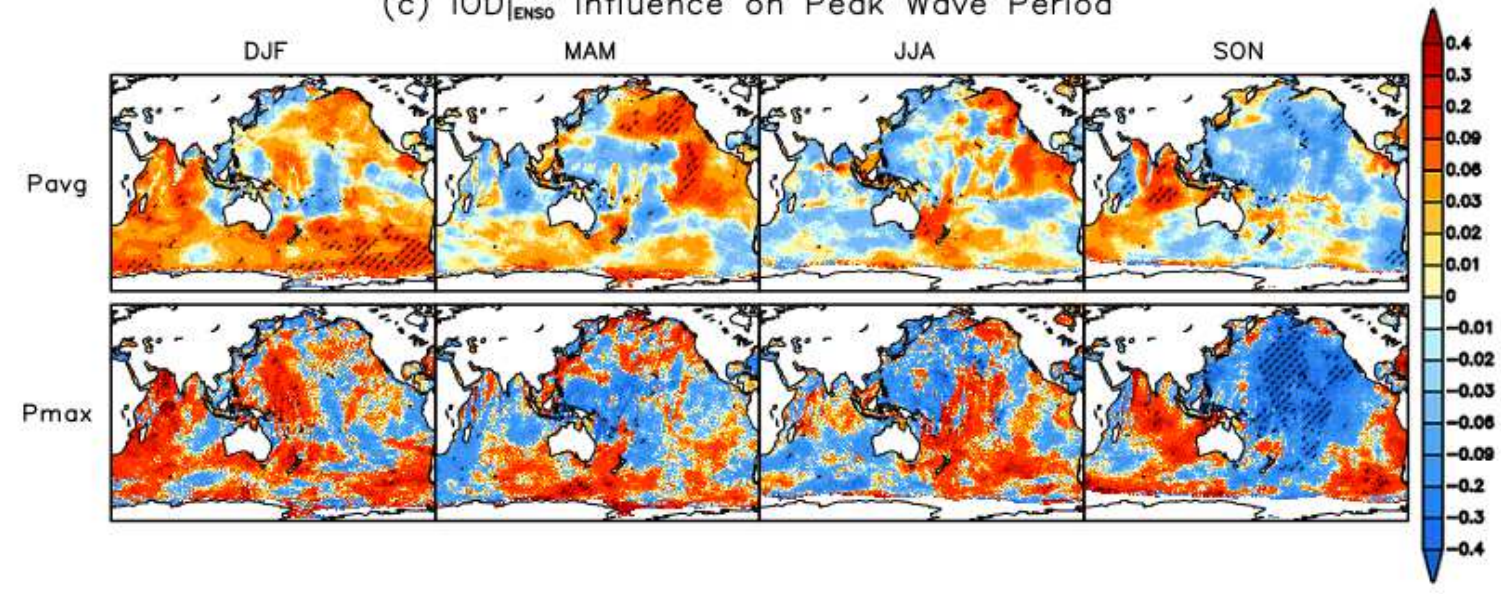

830 Figure 3. As in Fig. 2, but for the seasonal IOD influence independent of ENSO (denoted as

$\left.\left.831 \mathrm{IOD}\right|_{\text {ENSO }}\right)$, obtained after the removal of ENSO signals. 
(a) ENSO|Poo Influence on Wave Power

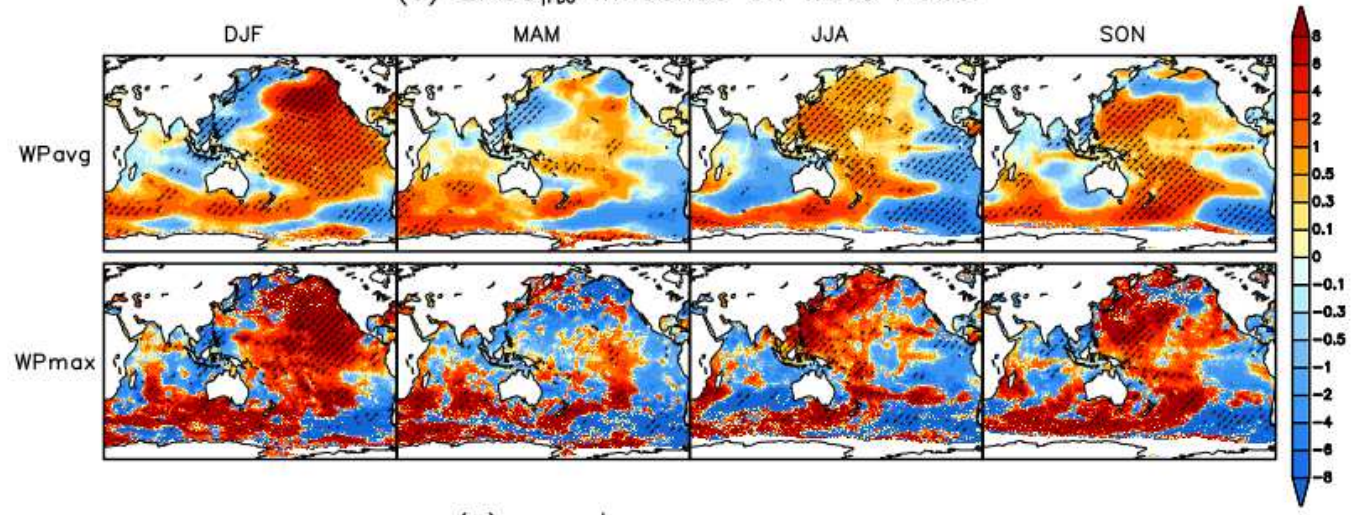

(b) ENSO|poo Influence on SWH

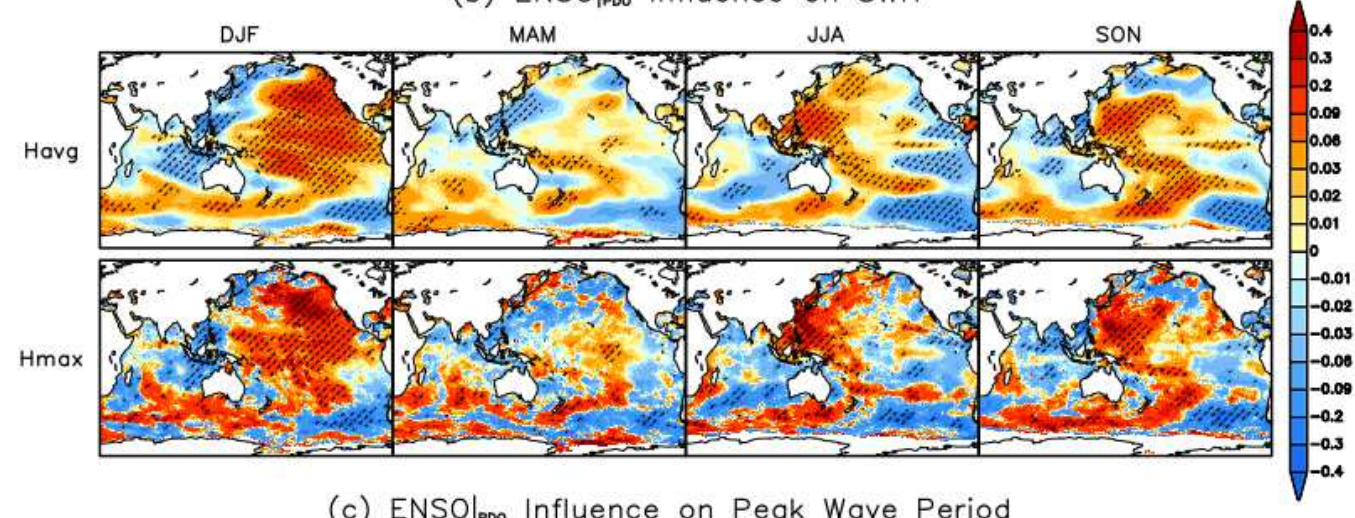

(c) ENSO|Poo Influence on Peak Wave Period

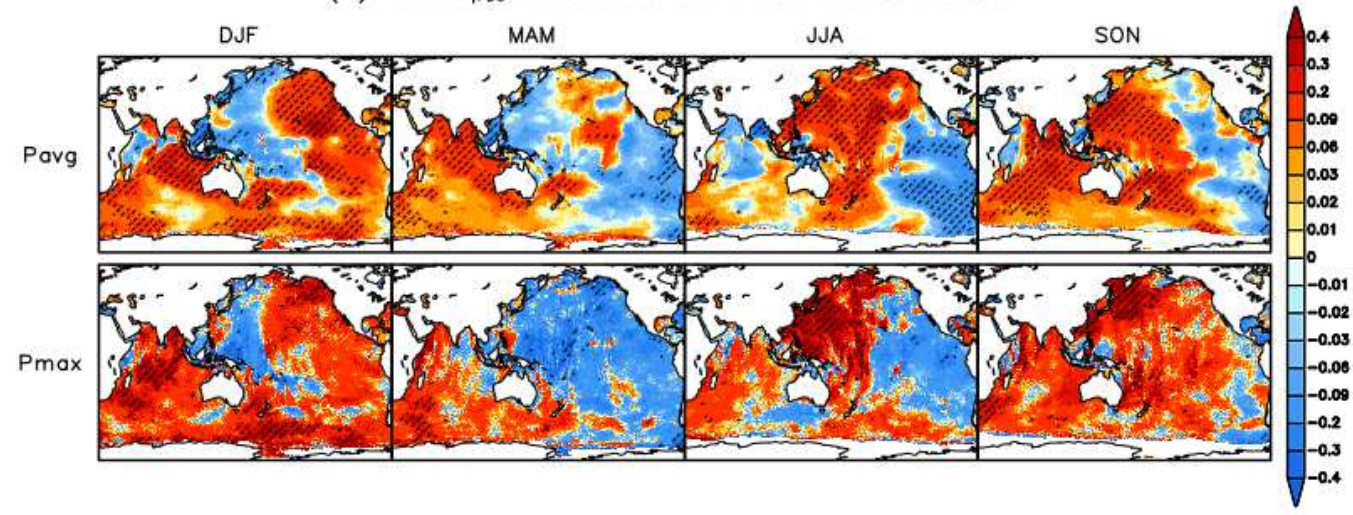

833 Figure 4. As in Fig. 2, but for the seasonal ENSO influence independent of PDO (denoted as

834 ENSO|$\left.\left.\right|_{\mathrm{PDO}}\right)$, obtained after the removal of PDO signals. 
(a) PDO| $\left.\right|_{\text {enso }}$ Influence on Wave Power

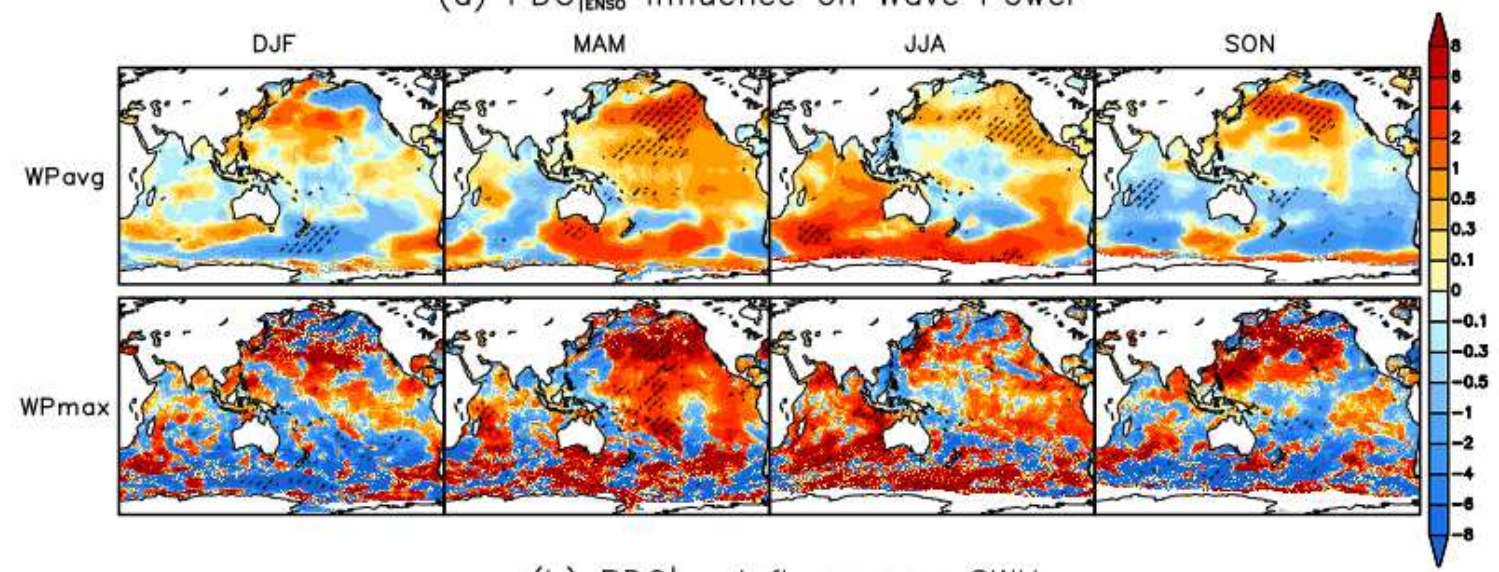

(b) PDO| Enso Influence on SWH

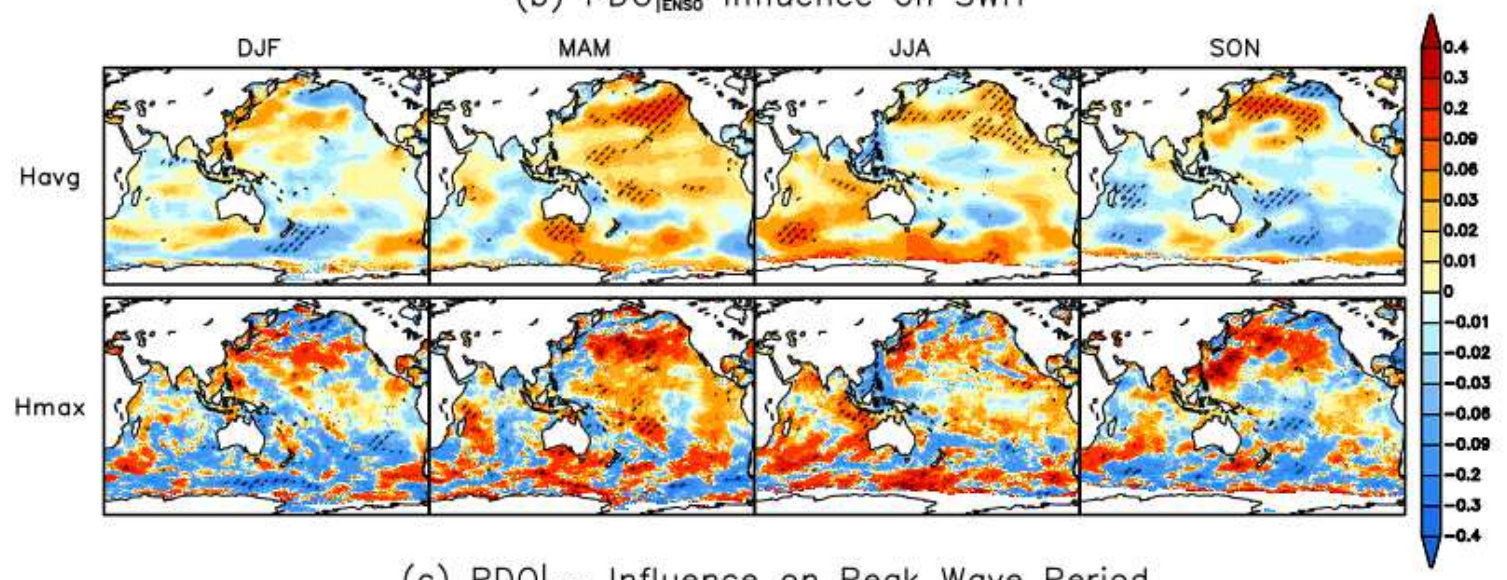

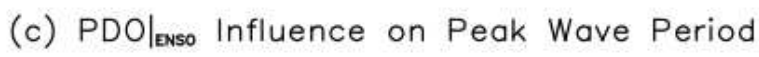

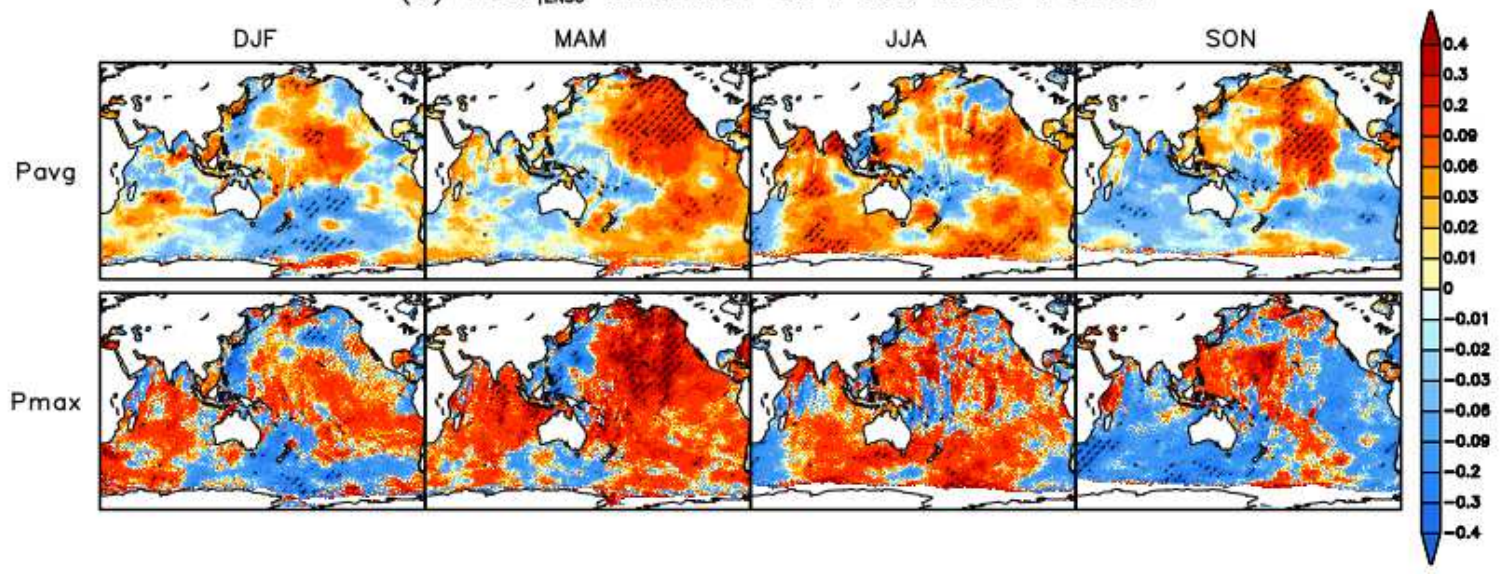

837 Figure 5. As in Fig. 2, but for the seasonal PDO influence independent of ENSO (denoted as

838 PDO|ENSO), obtained after the removal of ENSO signals. 
(a) JJA
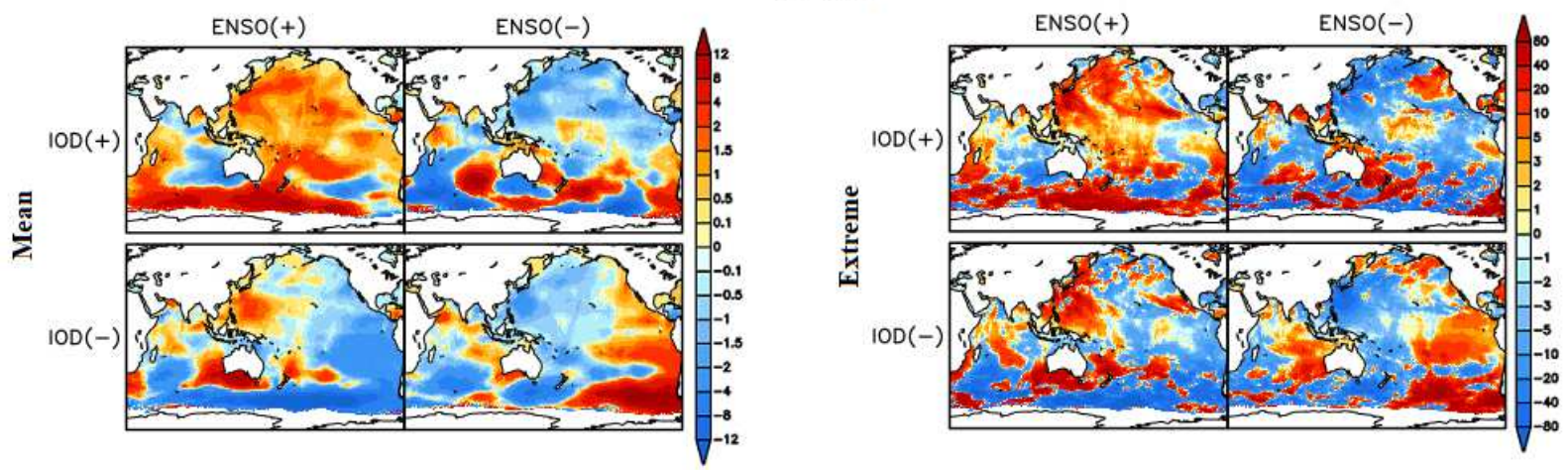

(b) SON
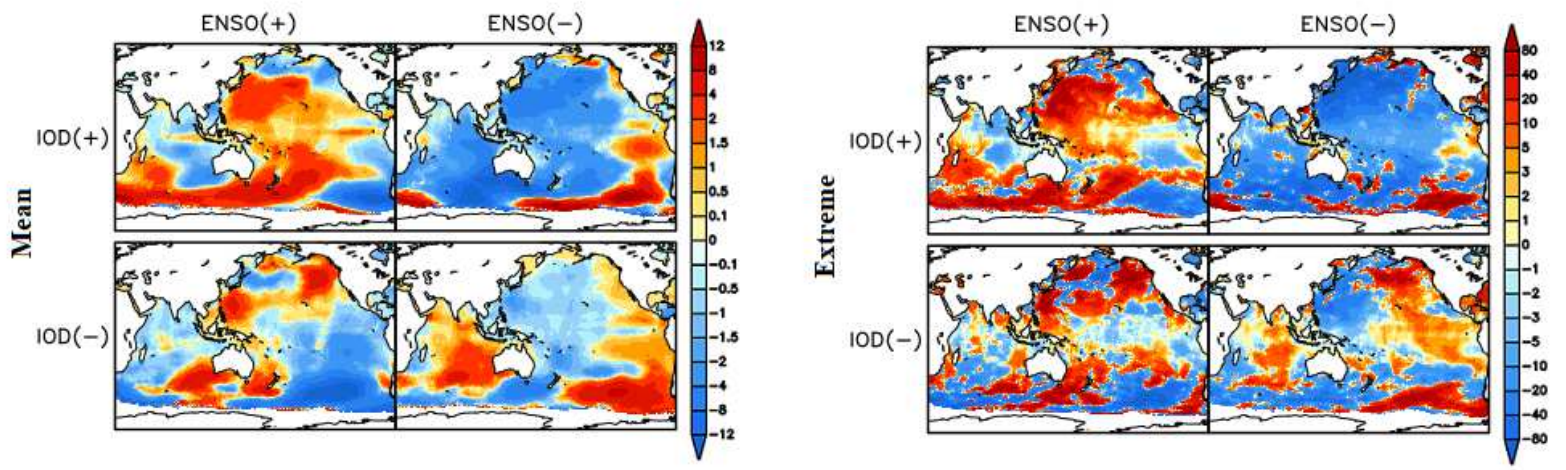

841

842 Fig. 6. Composite patterns of mean WP (left panels) and extreme WP anomalies (right panels)

843 during (a) JJA and (b) SON for the four different combinations of ENSO and IOD: El

844 Niño/pIOD, La Niña/pIOD, El Niño/nIOD, and La Niña/nIOD over the 41 year period from 845 1979-2019 (see list of years in Table 3). 


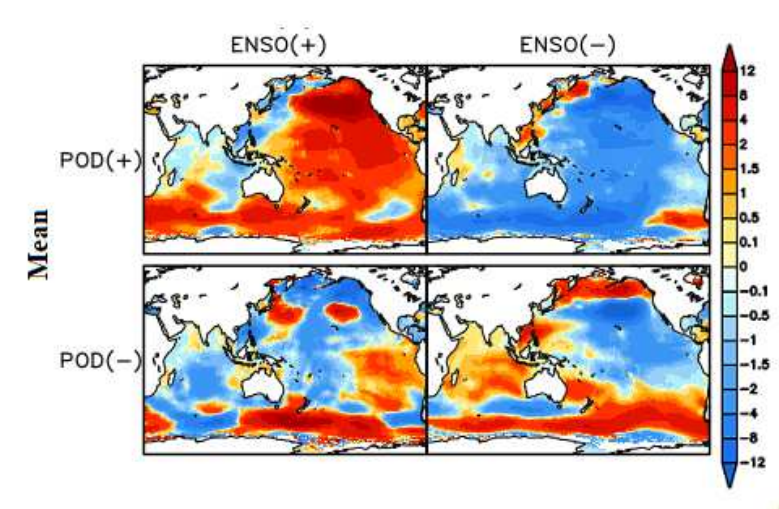

(a) DJF

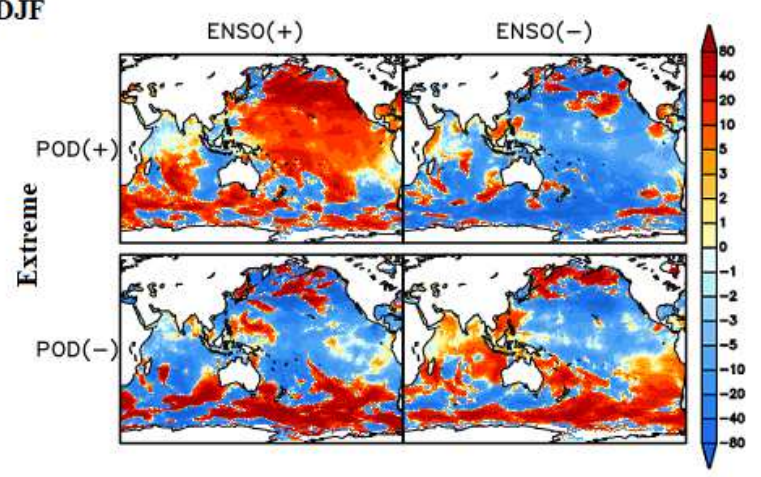

(b) MAM
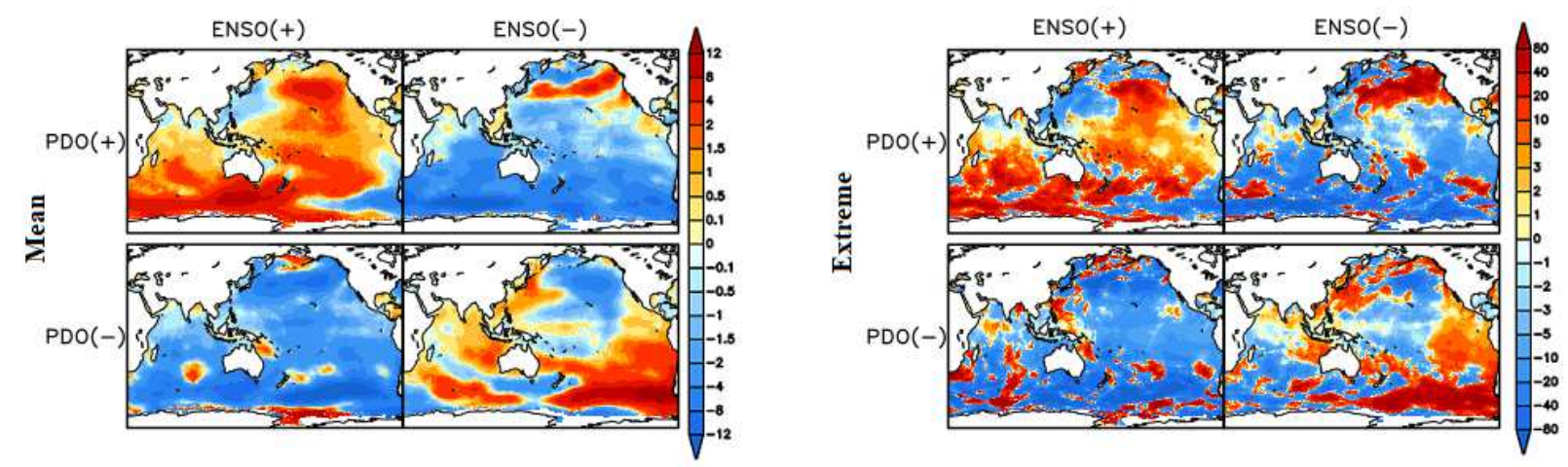

(c) $\mathrm{JJA}$
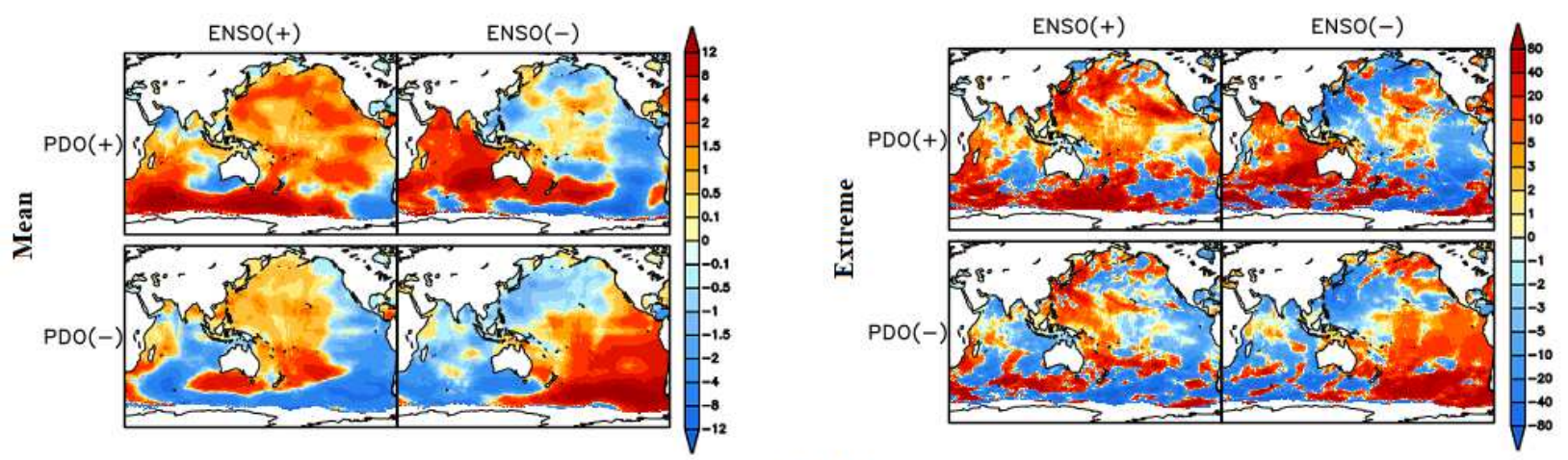

(d) $\mathrm{SON}$
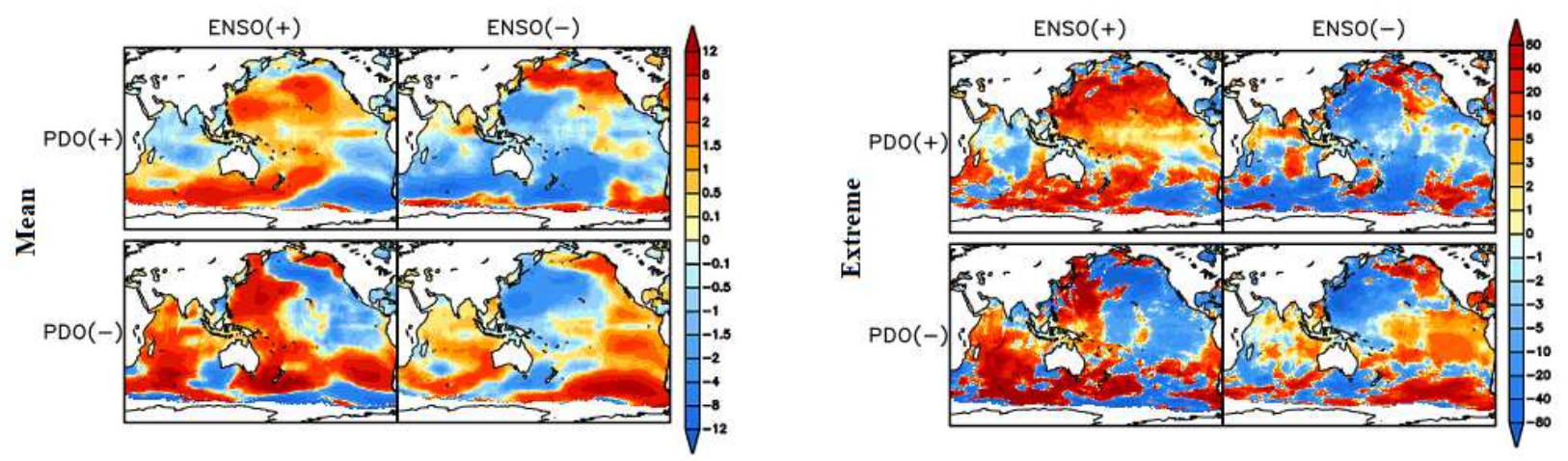
847 Fig. 7. Composite patterns of mean WP (left panel) and extreme WP anomalies (right pannel)

848 during (a) DJF, (b) MAM, (c) JJA, and (d) SON for the four different combinations of ENSO

849 and PDO: El Niño/pPDO, La Niña/pPDO, El Niño/nPDO, and La Niña/nPDO over the 41 year

850 period from 1979-2019 (see list of years in Table 4).

851

852

853

854

855

856

857

858

859

860

861

862

863

864

865

866

867

868

869 
Figures

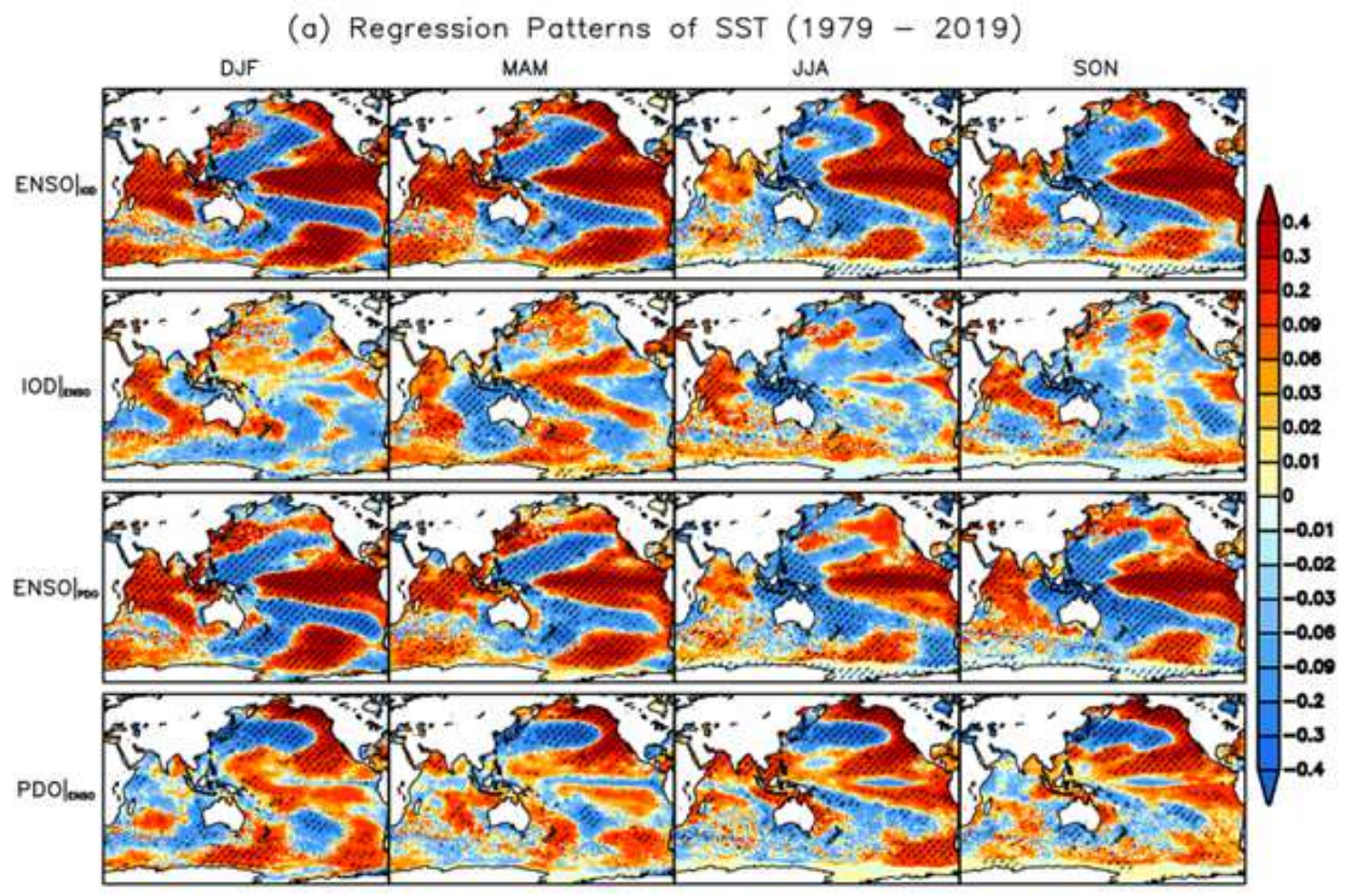

(b) Regression Patterns of SLP (1979 - 2019)

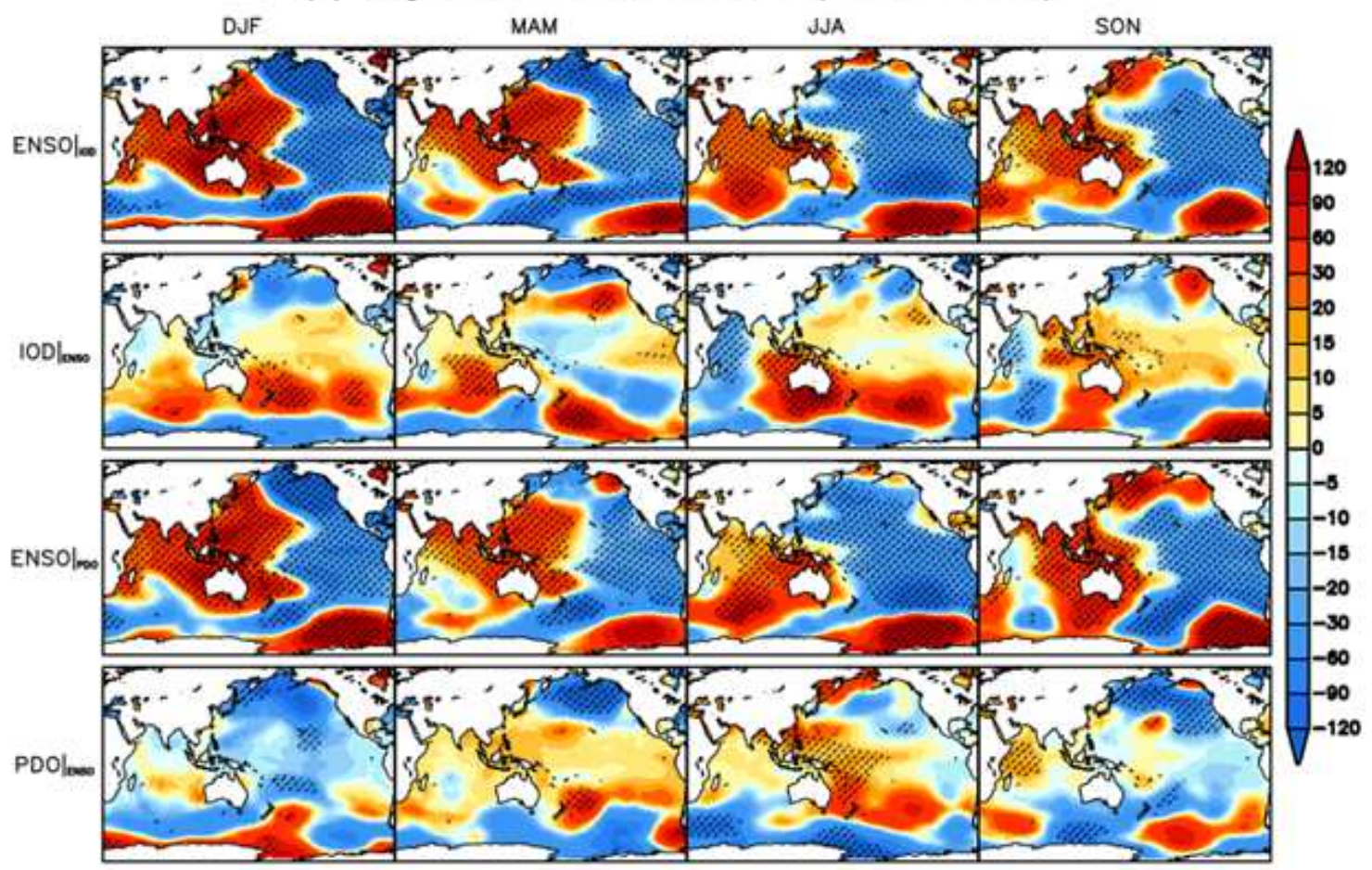

Figure 1

Seasonal regression patterns of mean (a) SST (in K) and (b) SLP (in Pa) onto ENSO|IOD, IOD|ENSO, ENSOIPDO, and PDO|ENSO in the Indo-Pacific Ocean over the period 1979-2019. Hatching represents the statistically significant regions at the $5 \%$ level. Note: The designations employed and the presentation 
of the material on this map do not imply the expression of any opinion whatsoever on the part of Research Square concerning the legal status of any country, territory, city or area or of its authorities, or concerning the delimitation of its frontiers or boundaries. This map has been provided by the authors.

(a) ENSOl,oo Influence on Wave Power

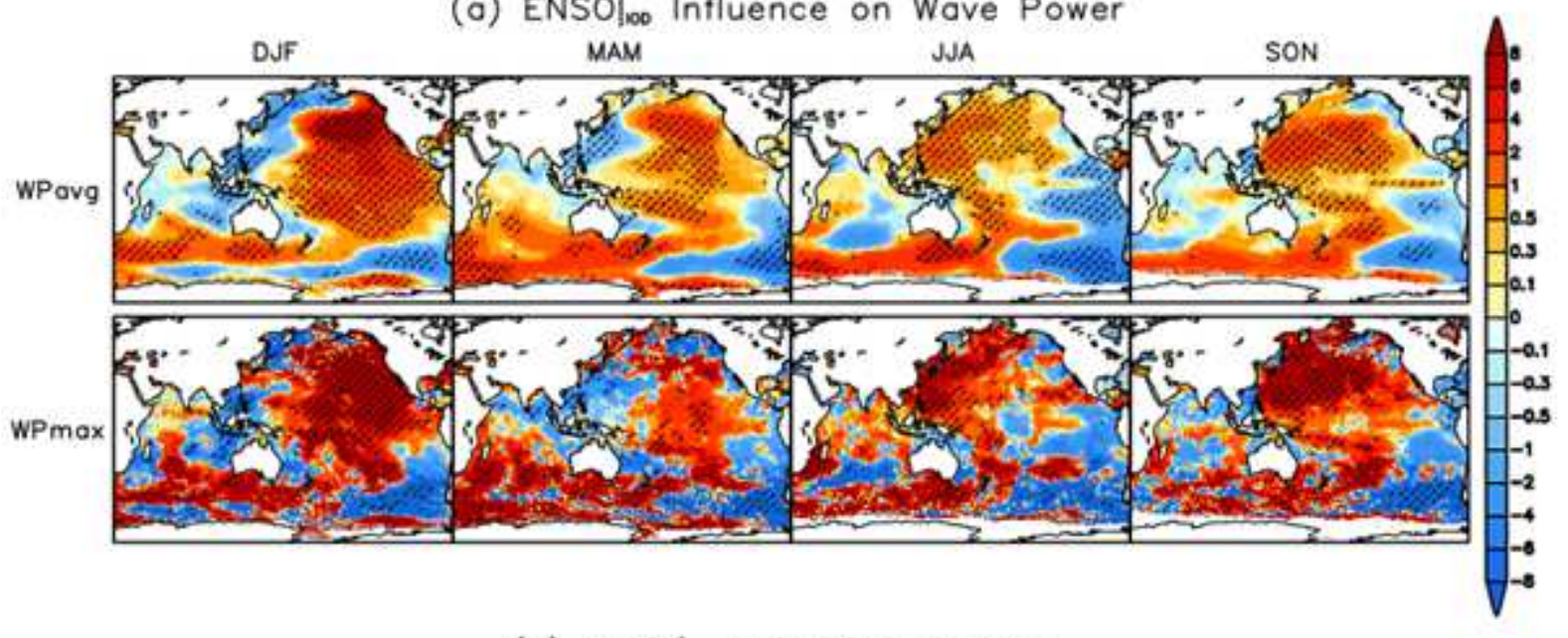

(b) ENSO| $\left.\right|_{\text {so }}$ Influence on SWH

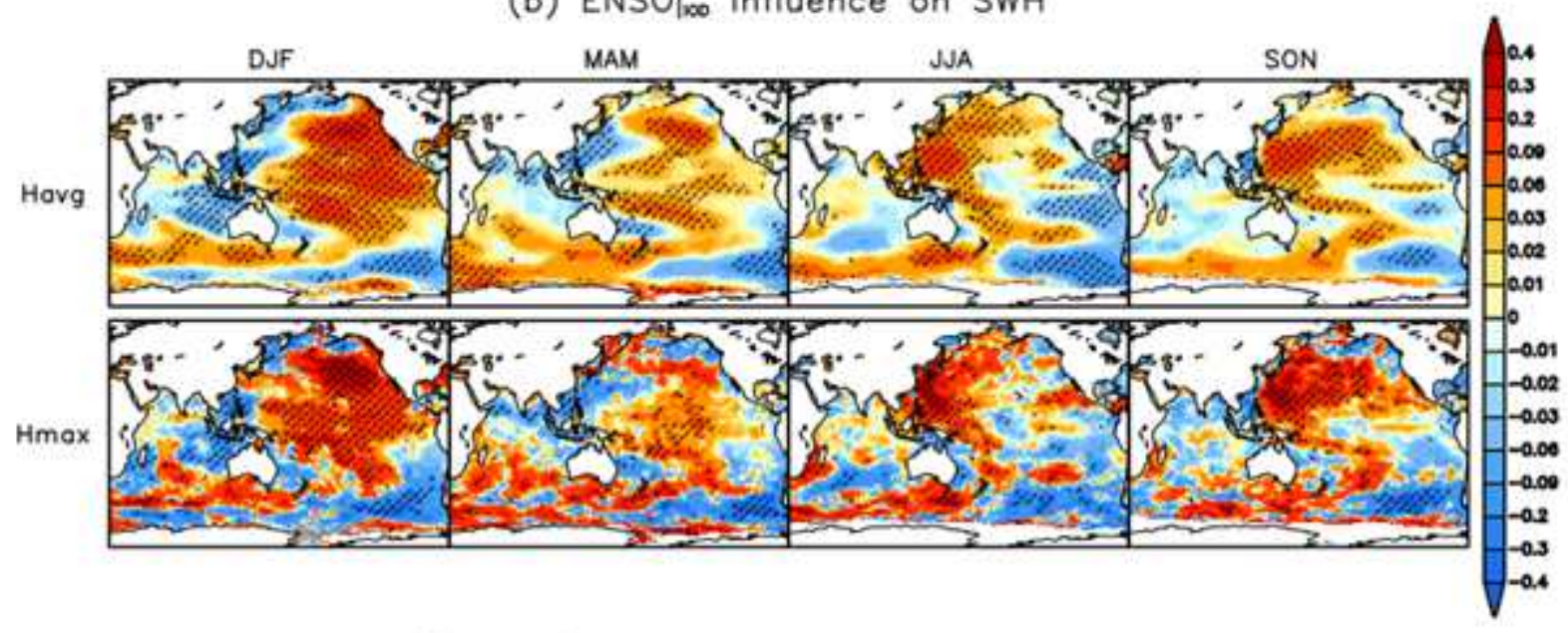

(c) ENSO| Influence on Peak Wave Period

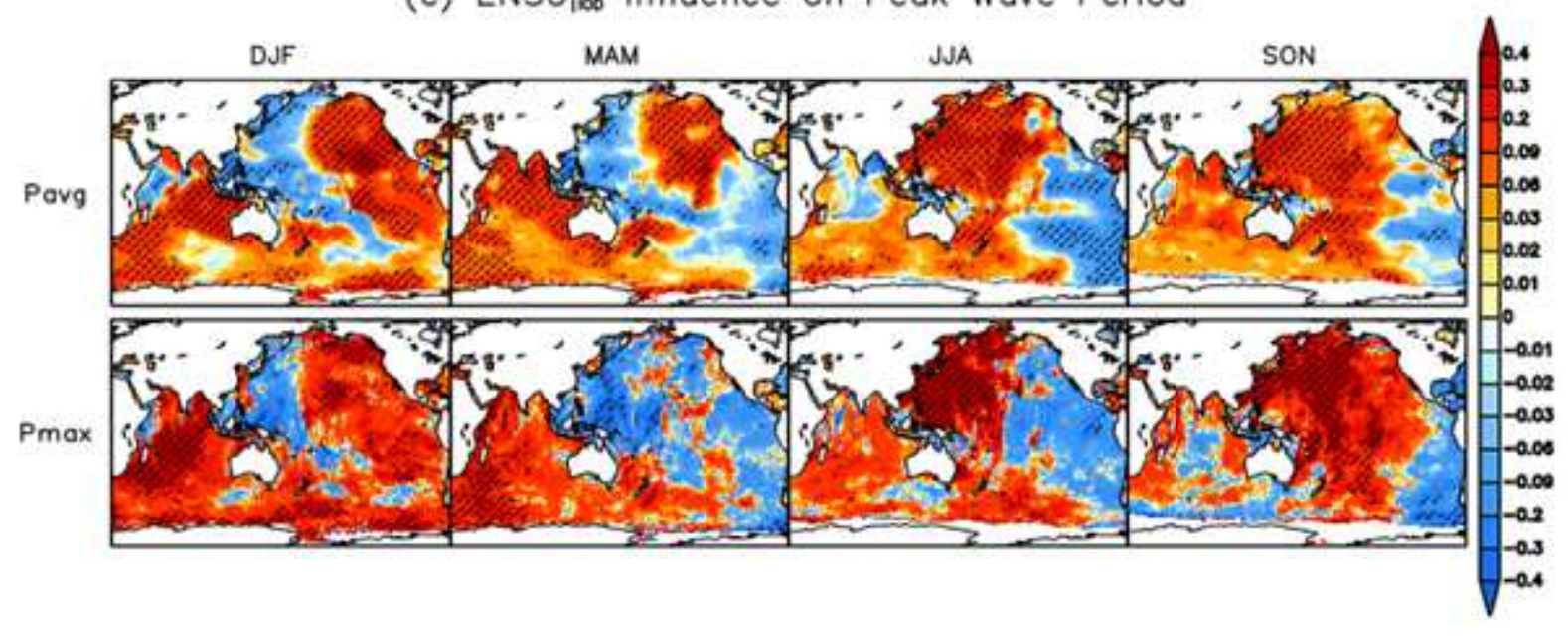

Figure 2

The seasonal ENSO influence independent of IOD (denoted as ENSO|IOD), obtained after the removal of IOD signals, on the mean and extreme WP (i.e., WPavg and WPmax), SWH (Havg and Hmax) and PWP 
(Pavg and Pmax) in the Indo-Pacific Ocean over the period 1979-2019. Hatching represents statistically significant regions at the $5 \%$ level. The unit of WP, SWH and PWP are given as kilowatts per meter $(\mathrm{kW} / \mathrm{m})$, meter $(\mathrm{m})$ and seconds $(\mathrm{s})$. Note: The designations employed and the presentation of the material on this map do not imply the expression of any opinion whatsoever on the part of Research Square concerning the legal status of any country, territory, city or area or of its authorities, or concerning the delimitation of its frontiers or boundaries. This map has been provided by the authors.

(a) $\left.10 D\right|_{\text {orso }}$ Influence on Wove Power

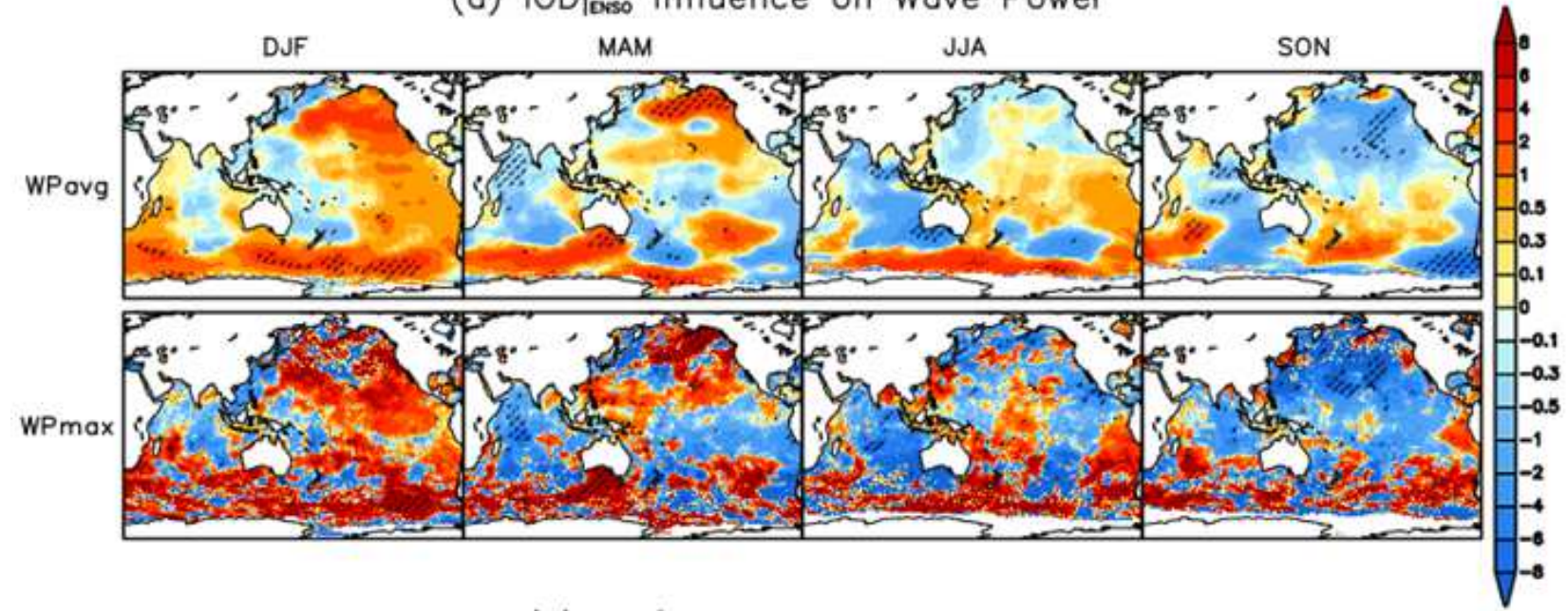

(b) IOD| enso Influence on SWH

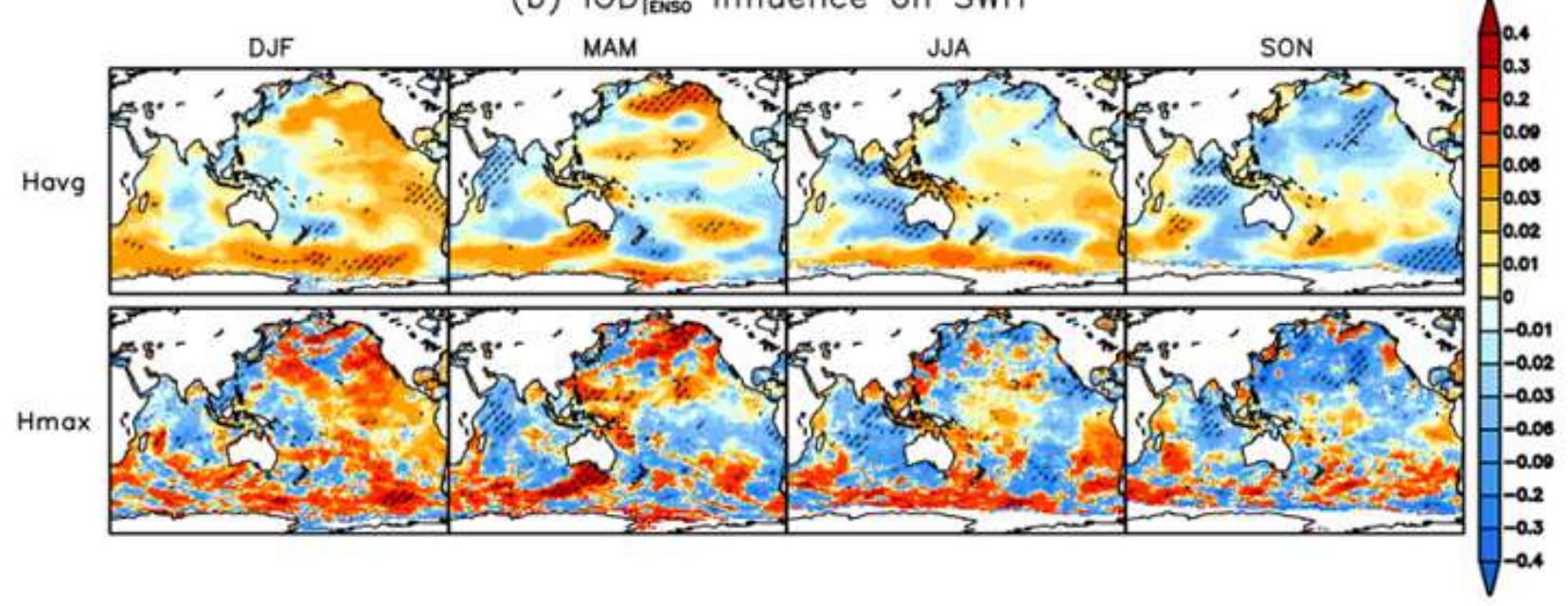

(c) $\left.I O D\right|_{\text {enso }}$ Influence on Peak Wave Period

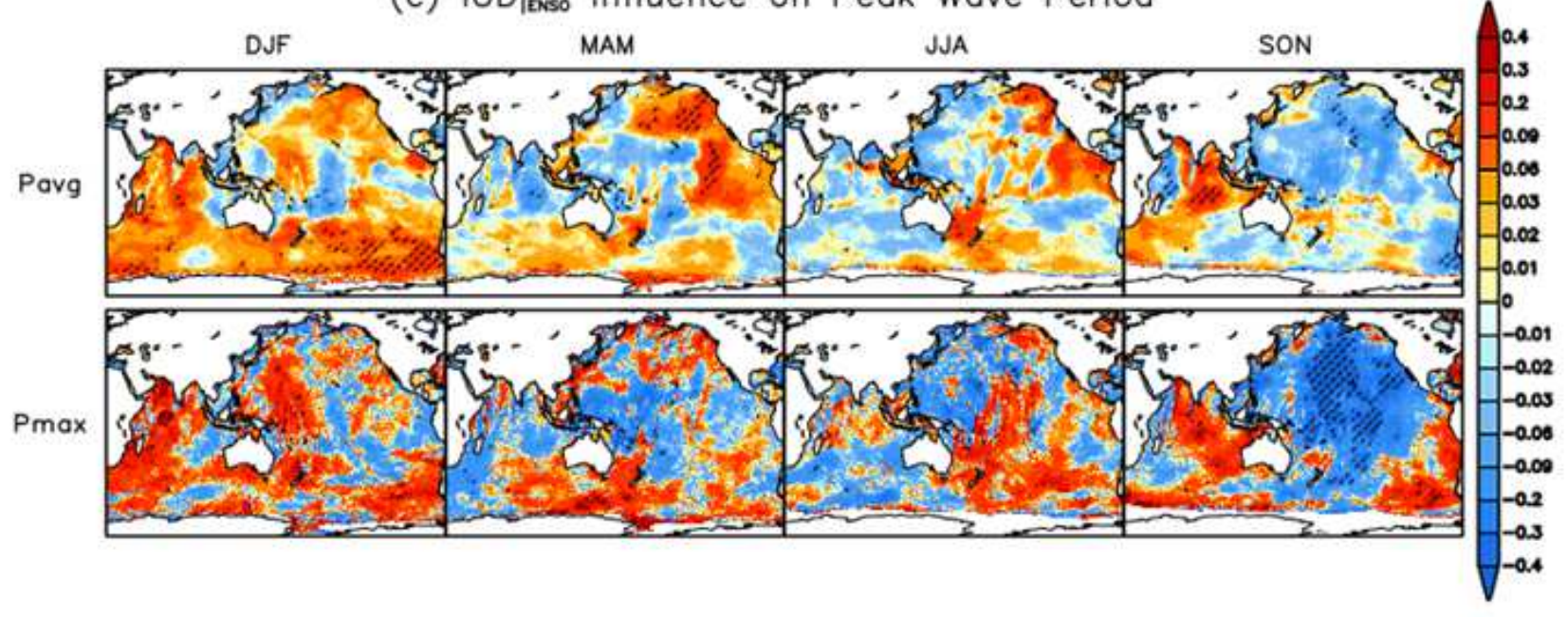

Figure 3 
As in Fig. 2, but for the seasonal IOD influence independent of ENSO (denoted as IOD|ENSO), obtained after the removal of ENSO signals. Note: The designations employed and the presentation of the material on this map do not imply the expression of any opinion whatsoever on the part of Research Square concerning the legal status of any country, territory, city or area or of its authorities, or concerning the delimitation of its frontiers or boundaries. This map has been provided by the authors.

(a) ENSO|poo Influence on Wave Power

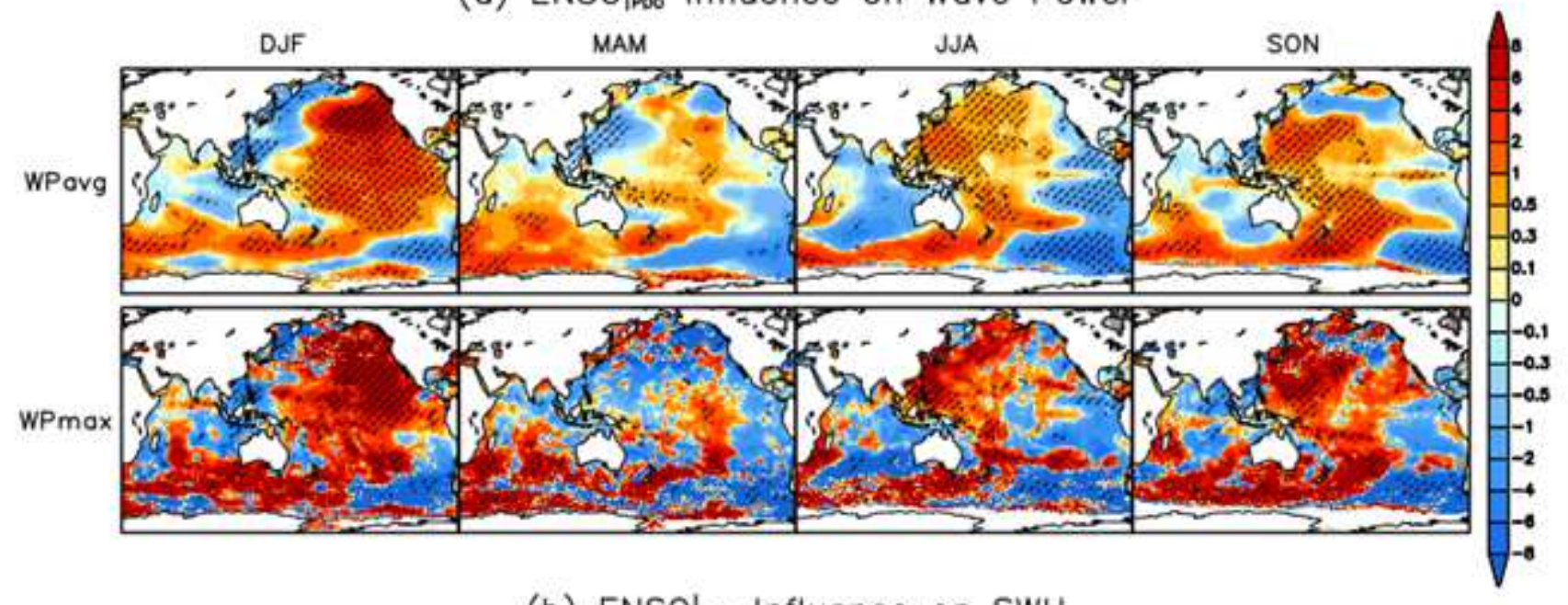

(b) ENSO|pos Influence on SWH

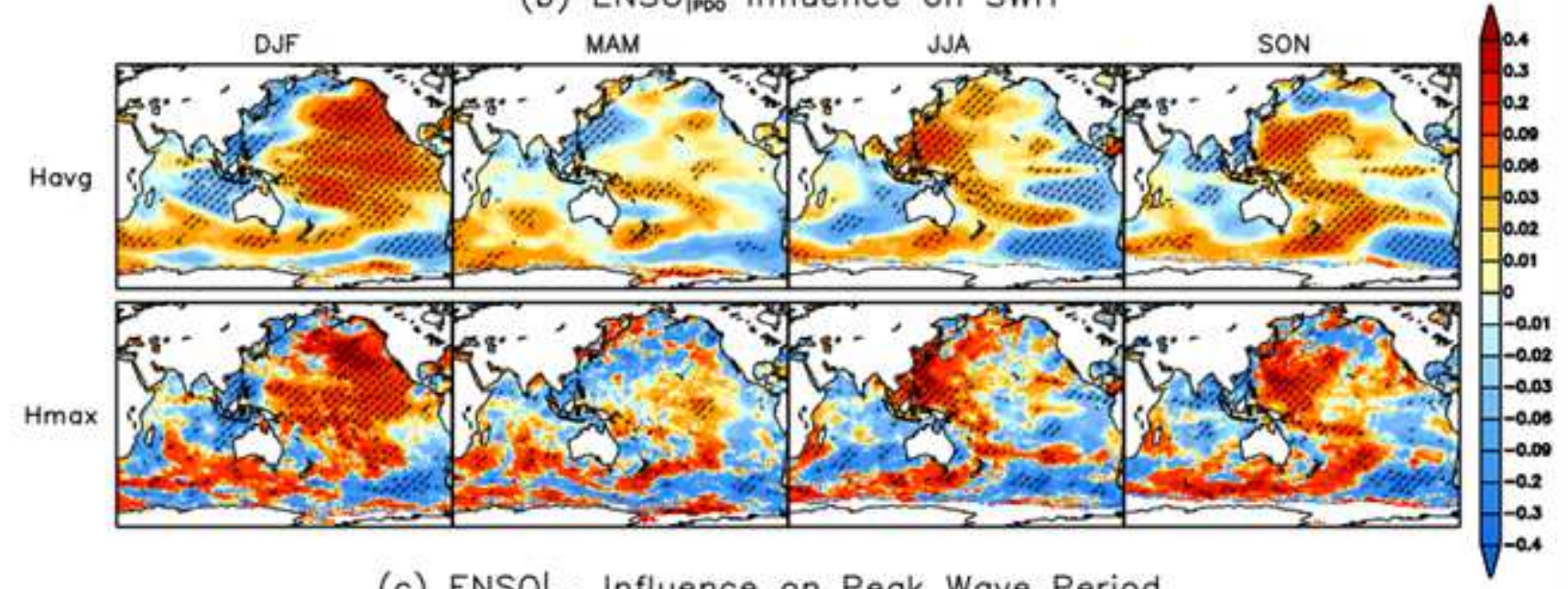

(c) ENSO| poo Influence on Peak Wave Period

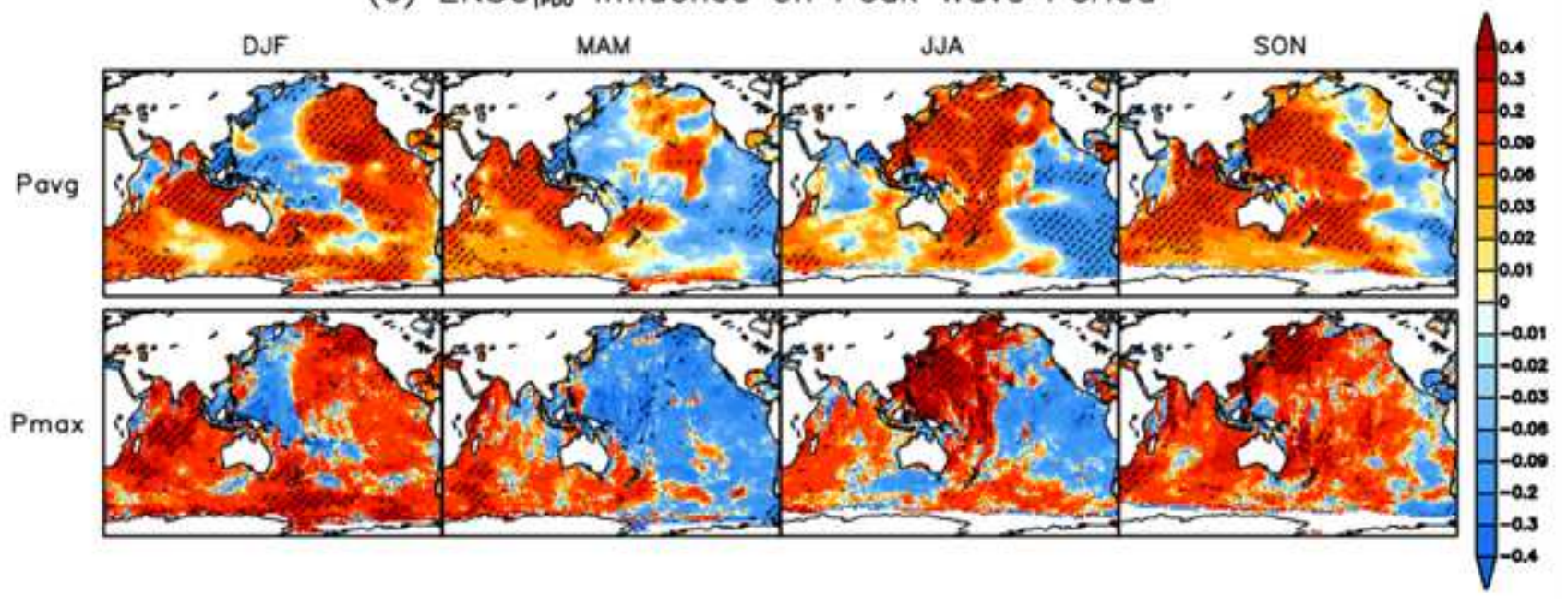

Figure 4 
As in Fig. 2, but for the seasonal ENSO influence independent of PDO (denoted as ENSO|PDO), obtained after the removal of PDO signals. Note: The designations employed and the presentation of the material on this map do not imply the expression of any opinion whatsoever on the part of Research Square concerning the legal status of any country, territory, city or area or of its authorities, or concerning the delimitation of its frontiers or boundaries. This map has been provided by the authors.

(a) PDO|
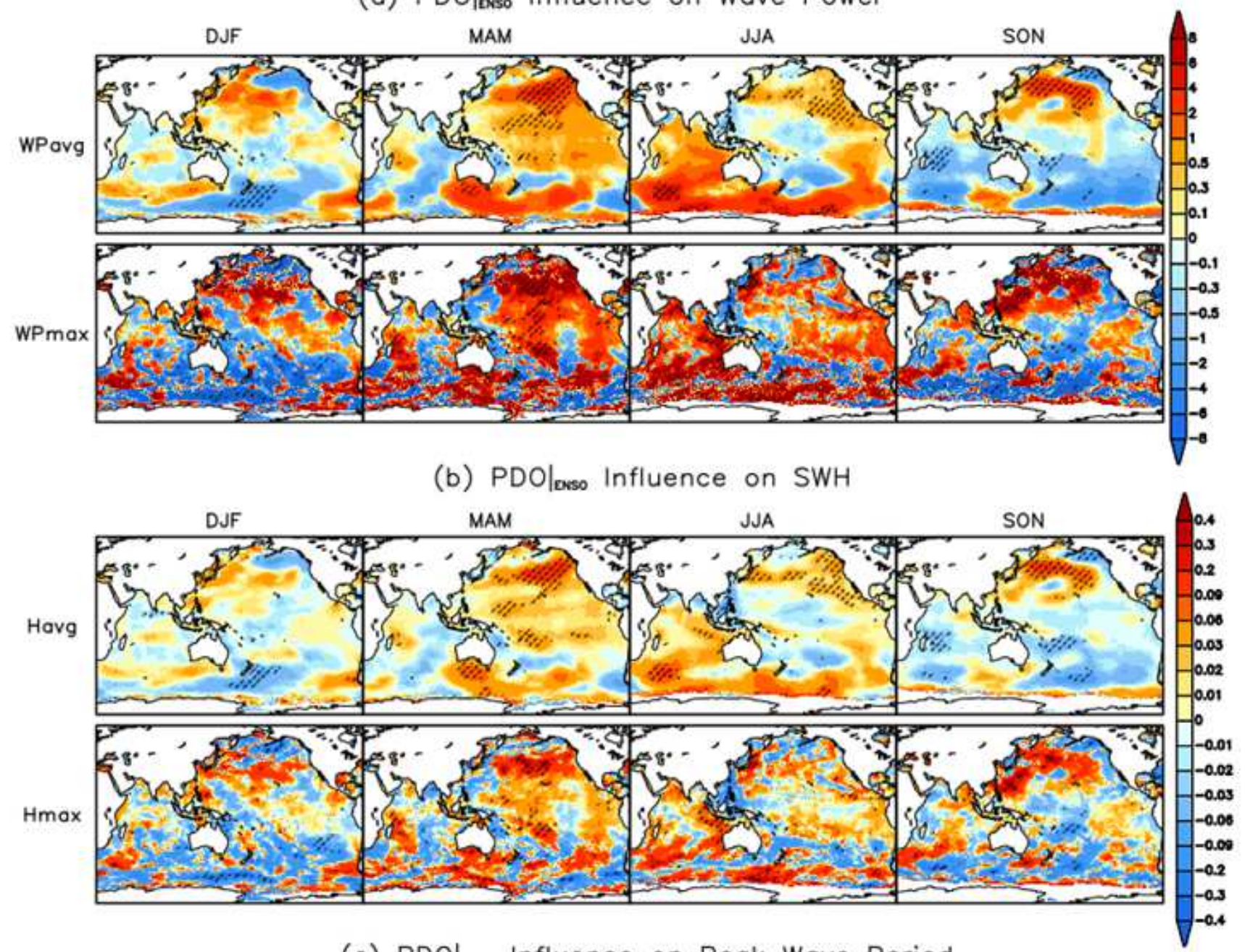

(c) PDO| $\left.\right|_{\text {ovso }}$ Influence on Peak Wave Period

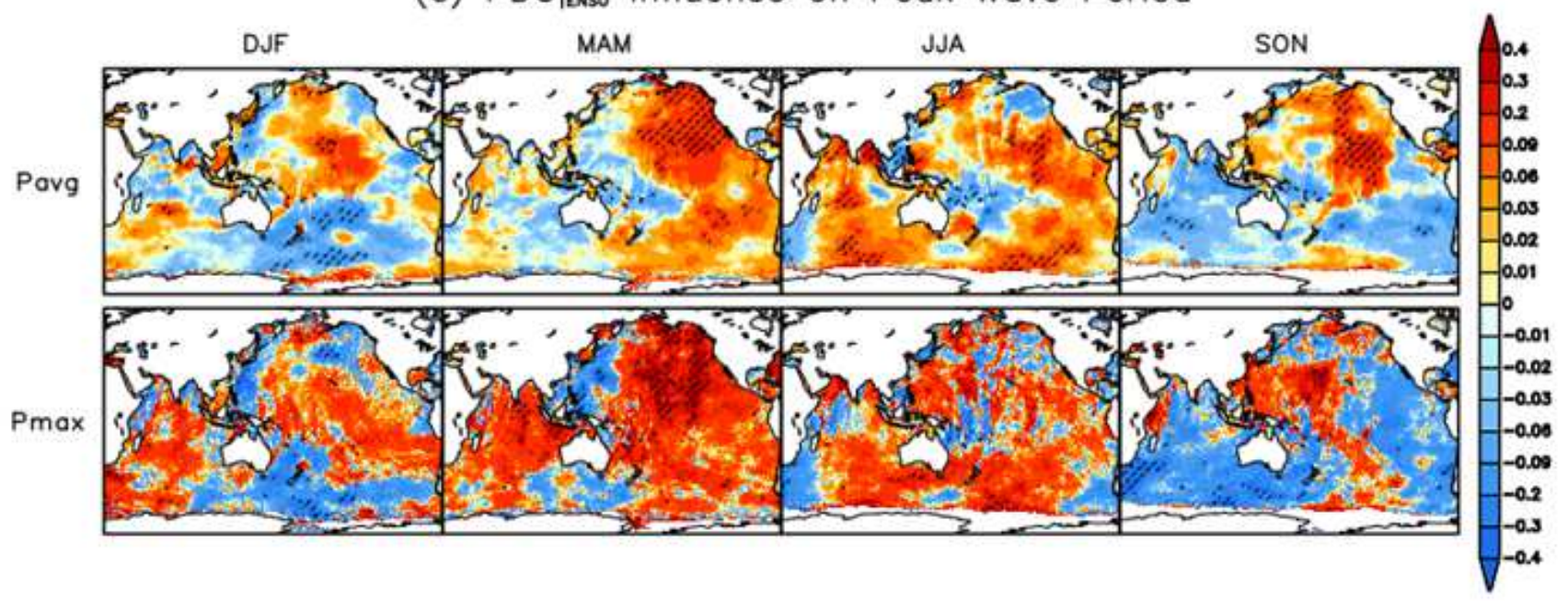

Figure 5 
As in Fig. 2, but for the seasonal PDO influence independent of ENSO (denoted as PDO|ENSO), obtained after the removal of ENSO signals. Note: The designations employed and the presentation of the material on this map do not imply the expression of any opinion whatsoever on the part of Research Square concerning the legal status of any country, territory, city or area or of its authorities, or concerning the delimitation of its frontiers or boundaries. This map has been provided by the authors.

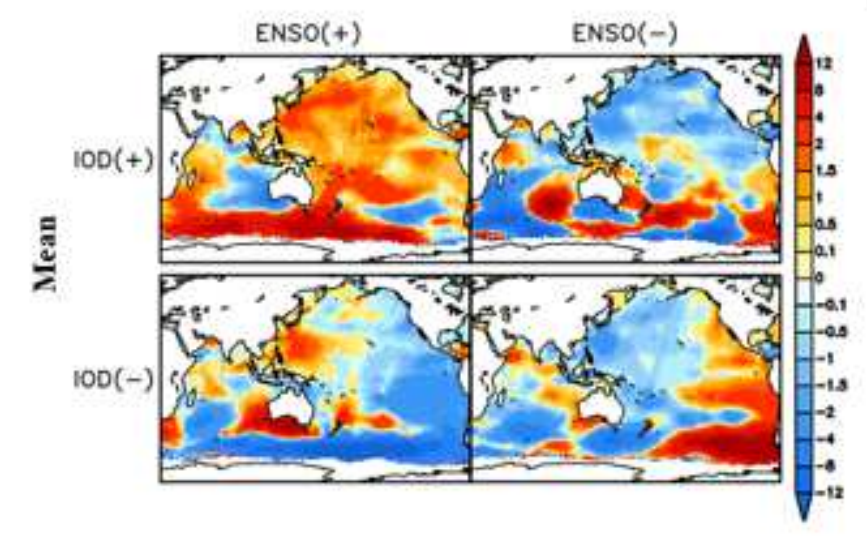

(a) JJA

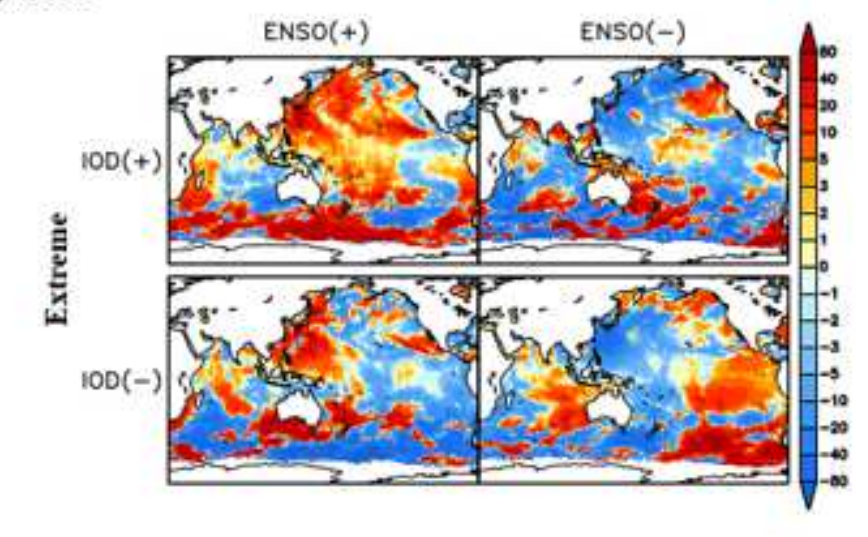

(b) SON
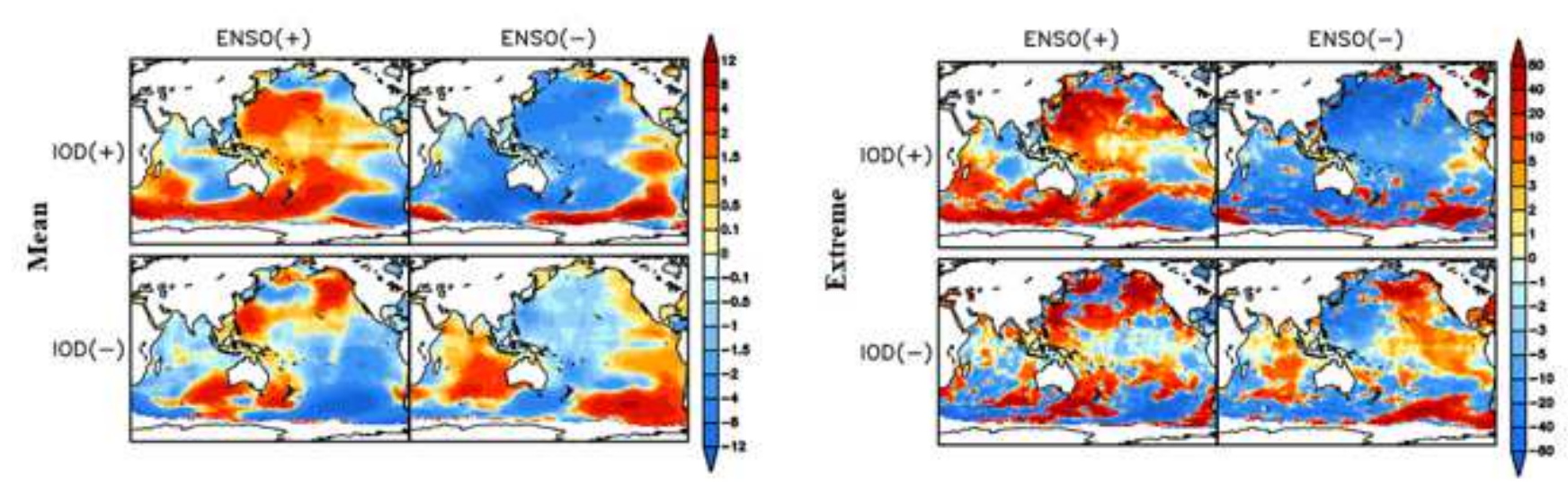

\section{Figure 6}

Composite patterns of mean WP (left panels) and extreme WP anomalies (right panels) during (a) JJA and (b) SON for the four different combinations of ENSO and IOD: El Niño/pIOD, La Niña/pIOD, El Niño/nIOD, and La Niña/nIOD over the 41 year period from 1979-2019 (see list of years in Table 3). Note: The designations employed and the presentation of the material on this map do not imply the expression of any opinion whatsoever on the part of Research Square concerning the legal status of any country, territory, city or area or of its authorities, or concerning the delimitation of its frontiers or boundaries. This map has been provided by the authors. 


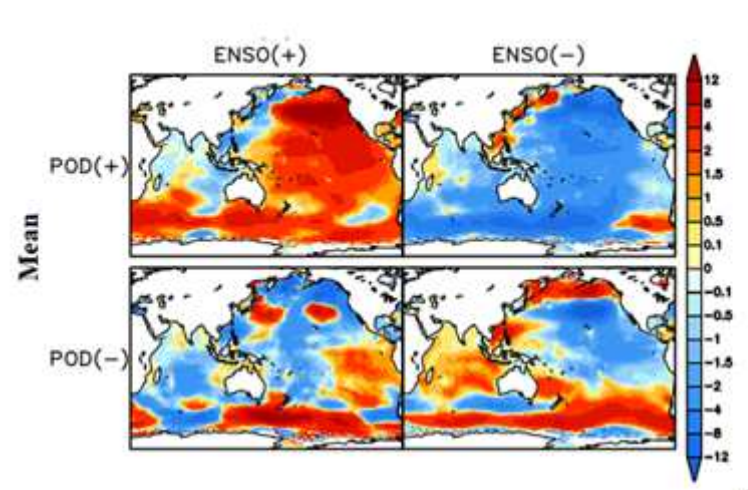

(a) DJF

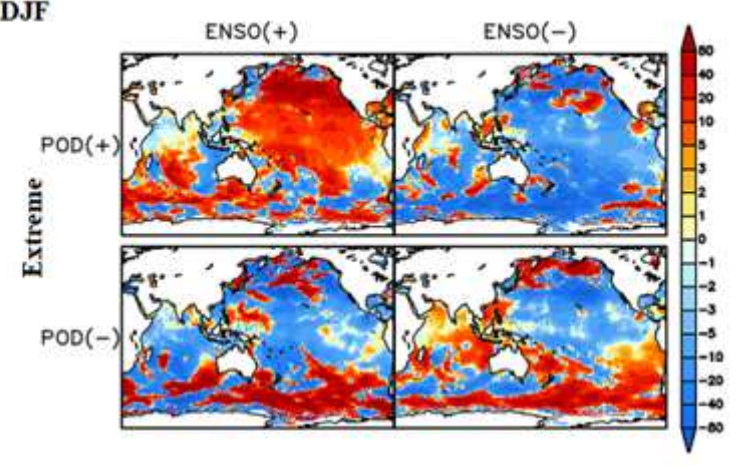

(b) MAM
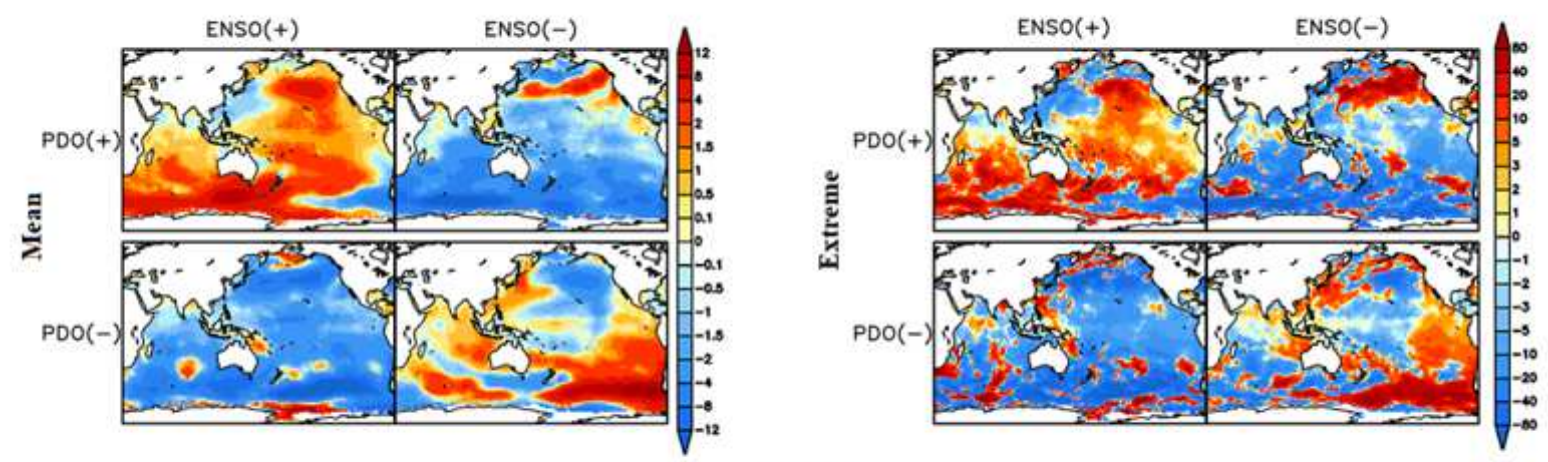

(c) JJA
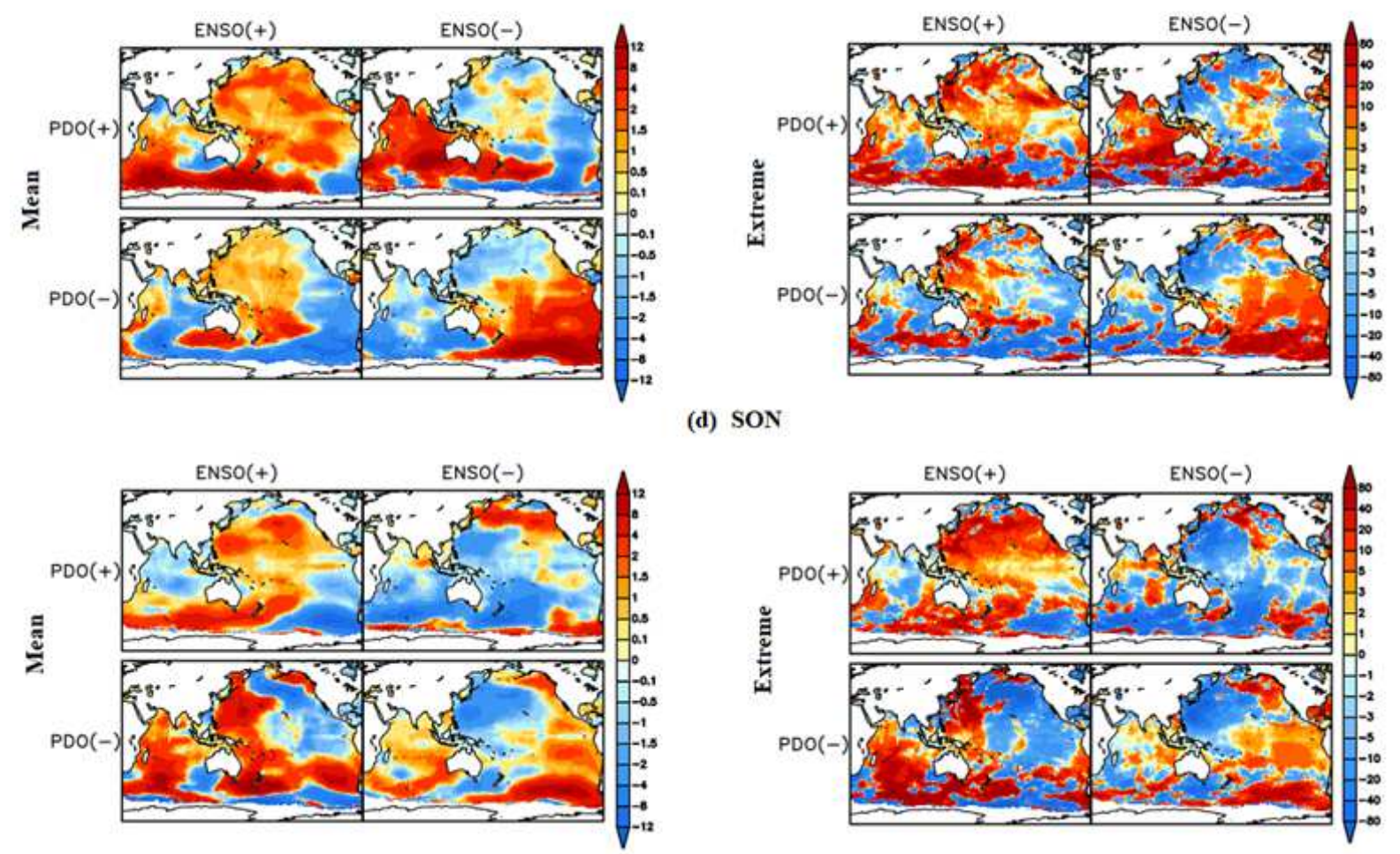

(d) SON

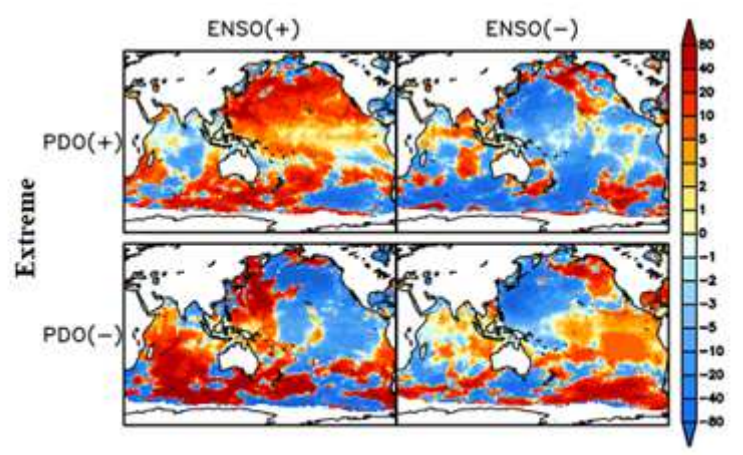

Figure 7

Composite patterns of mean WP (left panel) and extreme WP anomalies (right pannel) during (a) DJF, (b) MAM, (c) JJA, and (d) SON for the four different combinations of ENSO and PDO: El Niño/pPDO, La Niña/pPDO, El Niño/nPDO, and La Niña/nPDO over the 41 year period from 1979-2019 (see list of years in Table 4). Note: The designations employed and the presentation of the material on this map do not imply the expression of any opinion whatsoever on the part of Research Square concerning the legal 
status of any country, territory, city or area or of its authorities, or concerning the delimitation of its frontiers or boundaries. This map has been provided by the authors.

\section{Supplementary Files}

This is a list of supplementary files associated with this preprint. Click to download.

- Supplimentryfigures.docx 